\title{
Buckling Testing and Analysis of Honeycomb Sandwich Panel Arc Segments of a Full-Scale Fairing Barrel: Comparison of In- and Out-of-Autoclave Facesheet Configurations
}

\author{
Evan J. Pineda ${ }^{1}$ and David E. Myers ${ }^{2}$ \\ NASA Glenn Research Center, Cleveland, OH, 44135, U.S.A. \\ Daniel N. Kosareo ${ }^{3}$ \\ Vantage Partners, LLC, Brook Park, OH, 44142, U.S.A. \\ and \\ Bart F. Zalewski ${ }^{4}$ \\ ZIN Technologies, Inc., Middleburg Heights, OH, 44130, U.S.A. \\ Sotiris Kellas ${ }^{5}$ and Genevieve D. Dixon ${ }^{6}$ \\ NASA Langley Research Center, Hampton, VA, 23681, U.S.A. \\ and \\ Thomas M. Krivanek ${ }^{7}$ and Thomas G. Gyekenyesi ${ }^{8}$ \\ NASA Glenn Research Center, Cleveland, OH, 44135, U.S.A.
}

\begin{abstract}
Four honeycomb sandwich panels, representing 1/16th arc segments of a 10-m diameter barrel section of the Heavy Lift Launch Vehicle, were manufactured and tested under the NASA Composites for Exploration and the NASA Constellation Ares V programs. Two configurations were chosen for the panels: 6-ply facesheets with 1.125 in. honeycomb core and 8-ply facesheets with 1.0 in. honeycomb core. Additionally, two separate carbon fiber/epoxy material systems were chosen for the facesheets: in-autoclave IM7/977-3 and out-of-autoclave T40-800b/5320-1. Smaller $3 \mathrm{ft}$. by $5 \mathrm{ft}$. panels were cut from the 1/16th barrel sections and tested under compressive loading. Furthermore, linear eigenvalue and geometrically nonlinear finite element analyses were performed to predict the compressive response of each $3 \mathrm{ft}$. by $5 \mathrm{ft}$. panel. To improve the robustness of the geometrically nonlinear finite element model, measured surface imperfections were included in the geometry of the model. Both the linear and nonlinear models yielded good qualitative and quantitative predictions. Additionally, it was correctly predicted that the panel would fail in buckling prior to failing in strength. Furthermore, several imperfection studies were performed to investigate the influence of geometric imperfections, fiber angle misalignments, and three-dimensional effects on the compressive response of the panel.
\end{abstract}

${ }^{1}$ Aerospace Research Engineer, Mechanics and Life Prediction Branch, 21000 Brookpark Rd., MS 49-7, AIAA Member.

${ }^{2}$ Aerospace Engineer, Applied Structural Mechanics Branch, 21000 Brookpark Rd., MS 86-10.

${ }^{3}$ Senior Mechanical Engineer, 6745 Engle Rd.

${ }^{4}$ Mechanical Engineer V, 3000 Aerospace Parkway, AIAA Senior Member.

${ }^{5}$ Aerospace Engineer, Structural and Thermal Systems Branch, 1 North Dryden St., MS 431.

${ }^{6}$ Aerospace Engineer, Structural and Thermal Systems Branch, 1 North Dryden St., MS 431.

${ }^{7}$ Aerospace Flight Systems Engineer, Systems Integration Branch, 21000 Brookpark Rd., MS 86-1.

${ }^{8}$ Aerospace Flight Systems Engineer, Systems Integration Branch, 21000 Brookpark Rd., MS 86-1. 


\section{Nomenclature}

$E=$ "UNISORB" V-100 modulus

$E_{c} \quad=$ Core modulus

$E_{f} \quad=$ Facesheet modulus

$E_{1}, E_{2}, E_{3} \quad=$ Core Young's moduli

$F_{c 1}, F_{c 2}, F_{c 3}=$ Core compressive strength

$F_{S 12}, F_{S I 3}, F_{s 23}=$ Core shear strength

$F_{t 1}, F_{t 2}, F_{t 3}=$ Core tensile strength

$G_{12}, G_{13}, G_{23}=$ Core shear moduli

MS $\quad=$ Margin of safety

sw $\quad=$ Wrinkling stress

$t \quad=$ Panel thickness

$t_{c} \quad=$ Core thickness

$t_{f} \quad=$ Facesheet thickness

$\Delta \quad=$ Nidplane disaplcement

$v \quad=$ "UNISORB" V-100 Poisson's ratio

$v_{f} \quad=$ Facesheet Poisson's ratio

$v_{12}, v_{13}, v_{23}=$ Core Poisson's ratio

$\rho \quad=$ Core density

$\sigma_{1}, \sigma_{2} \quad=$ Principal stresses

$\Phi \quad=$ Panel edge rotation

\section{Introduction}

S HELL buckling is a critical design criterion used in the design of aerospace structures. Cylindrical structures are Nextremely sensitive to imperfections, and as a result, it is challenging to predict the buckling response of these structures accurately. Thus, additional knockdown factors ( 0.65 in addition the ultimate 1.4 safety factor) must be imposed on the linear eigenvalue during design to ensure safety ${ }^{1,2}$. These original shell buckling knockdown factors were based on testing and analysis of metallic structures. Many current aerospace structures utilize advanced carbon fiber reinforced composite materials. However, the knockdown factors have not been revised to account for uncertainties associated with the composite materials.

The shell buckling knockdown factors incorporate the sensitivity (or uncertainty in behavior) to a number of different types of imperfections. However, a single knockdown factor is used regardless of the level of influence of the particular imperfections on the structure of interest. Moreover, the shell buckling design standards for metallic structures have not been updated in over 50 years. The knockdown factors can be especially impactful on the design of composite structures and may, in some cases, negate the weight, stiffness, and strength savings offered from the use of such materials.

Efforts are currently underway to formulate more comprehensive shell buckling knockdown factors for metallic structures $^{3-5}$. The work presented in this manuscript represents some preliminary experimental and analytical investigations into the potential manufacturing defects, and other imperfections, that may affect the stability of fullscale cylindrical, composite structures.

Five $3.0 \mathrm{ft}$. by $5.0 \mathrm{ft}$. panels were cut from four manufacturing demonstration panels. The configurations of these panels and other details are summarized in Section II. These panels were tested under compression, at the NASA Langley Research Center (LaRC) until buckling occurred. Several, supplementary finite element analysis (FEA) techniques were utilized to predict the buckling load of each panel. These methods included linear eigenvalue analysis of two-dimensional (2-D) and three-dimensional (3-D) models, and geometrically non-linear progressive collapse simulation of 2-D and 3-D models. Geometric imperfection data measured from the test panels was incorporated into the finite element models. In addition to the blind predictions, several imperfection studies were performed to explore the sensitivity of the panels to potential manufacturing defects, such as geometric imperfections, fiber misalignment, and loading eccentricity. The experimental and analytical results for all five panels are summarized in this manuscript. For complete details on the individual panels, the reader is referred to Refs. 6-9. 


\section{Experimental Details}

\section{II.A. 1/16 ${ }^{\text {th }}$ Panel Description}

Two manufacturing demonstration honeycomb sandwich panels (1/16th arc segments of the $10.0 \mathrm{~m}$ diameter barrel section of the Heavy Lift Launch Vehicle (HLLV) fairing) were fabricated under the NASA Composites for Exploration (CoEx) program and two under the NASA Constellation Ares V program. All four panels were manufactured by Hitco Carbon Composites. Two distinct configurations were chosen for the panels. The first configuration, fabricated under the CoEx program, was composed of 8-ply facesheets with a $\left[45^{\circ} / 90^{\circ} /-45^{\circ} / 0^{\circ}\right]_{\mathrm{s}}$ layup and $1.0 \mathrm{in.}$ aluminum honeycomb core. The second configuration, fabricated under the Constellation Ares $\mathrm{V}$ program, consisted of 6-ply facesheets with a $\left[60^{\circ} /-60^{\circ} / 0^{\circ}\right]_{\mathrm{S}}$ stacking sequence and a 1.125 in. aluminum honeycomb core. In addition to the two configurations, two different carbon fiber/epoxy facesheet material systems were chosen for the panels: in-autoclave (IA) IM7/977-3 and out-of-autoclave (OOA) T40-800b/5320-1. The 1/16th fabrication demonstration panels were constructed on a concave composite tool (5.0 m radius of curvature) using an automated tape laying process and 6 in. wide preimpregnated (pre-preg) tape composed of the aforementioned material systems. The facesheets were bonded to the aluminum core using FM 300 film adhesive with a density $0.08 \mathrm{lb} . / \mathrm{ft}^{2}$. It should also be noted that the honeycomb used in the 8-ply panels was Alcore PAACORE 5052, 0.0007 in thick with 0.125 in cell size, and a density of $3.1 \mathrm{pcf}$ and was machined to match the curvature of the panel. The honeycomb used in the 6-ply panels was flat, not machined to panel curvature dimension, and composed of HexWeb 5052, 0.0007 in thick with 0.125 in cell size, and a density of 3.1 pcf. Additionally, in each panel, A Hysol 9396.6 foaming adhesive was used to join (or splice) discontinuous sections of the honeycomb core because the 1/16th barrel section panel dimensions exceeded the size of the premanufactured core. The manufacturing demonstration

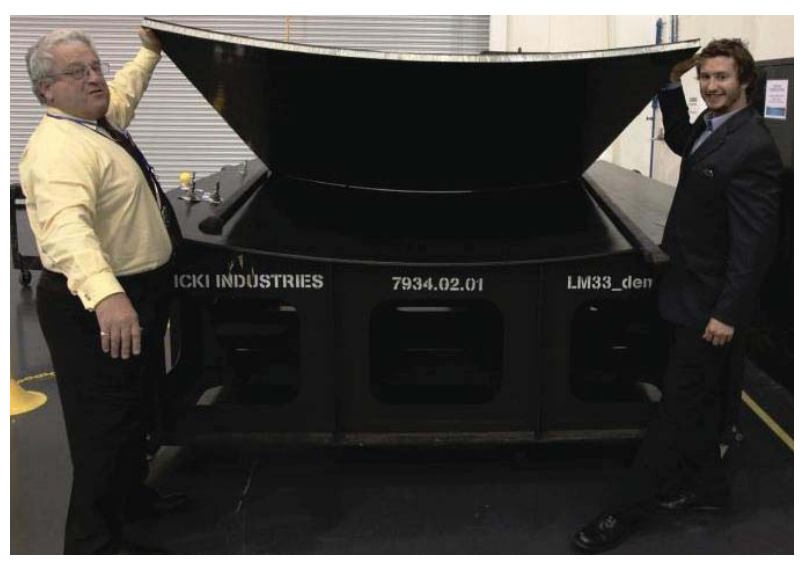

Figure 1. Cured 1/16th arc segment panel and the tool it was molded on.

1/16th arc segment (of a $5 \mathrm{~m}$ outside radius cylinder) panel is shown in Figure 1.

\section{II.B. Test Specimen Description}

Following delivery to NASA LaRC, non-destructive evaluation (NDE) inspection (including ultrasonic testing and flash thermography) was performed on the full manufacturing demonstration panel. The results of the NDE guided the decision on where to cut $36.0 \mathrm{in}$. wide by $62.0 \mathrm{in}$. long sections for edgewise compression buckling tests. Following removal of the 36.0 in. by $62.0 \mathrm{in}$. panels from the manufacturing demo, the panels were re-inspected using infrared (IR) thermography to ensure that no damage had occurred.

In preparation for testing, the load introduction ends of the panels were potted in 1.0 in thick aluminum end plates. The purpose of the end plates was to stabilize the facesheets and prevent local crushing, thus generating a predictable and repeatable end condition. As such, the panels are referred to as $3.0 \mathrm{ft}$. by $5.0 \mathrm{ft}$. according to the acreage dimensions of the test panels. The end plates were 1.0 in. thick aluminum plates with a slot in the shape of the specimens cross section machined in the center. Preliminary FEA indicated that no additional reinforcement was needed at the load introduction ends of the panels. The slot width and length were such that, when centered, the specimen had a clearance of 0.5 in around the perimeter. After the specimen-end was centered in the slot and squared, it was potted with "UNISORB" V-100 epoxy grout, see Figure 2. Following the potting and curing of each end plate the specimen ends were machined flat and parallel to within \pm 0.0025 in. A summary of the five $3.0 \mathrm{ft}$. by $5.0 \mathrm{ft}$. panels that were tested is given in Table 1.

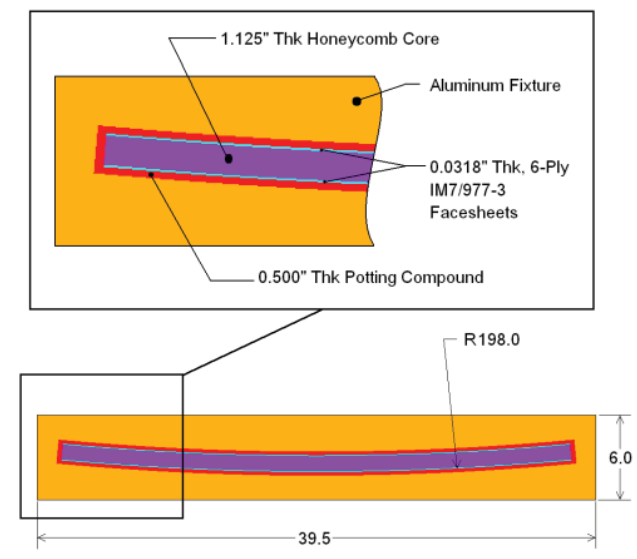

Figure 2. The $3^{\prime} \times 5^{\prime}$ arc segment test panel and test fixture end view. 
Table 1. Details of five $3 \mathrm{ft}$. wide by $5 \mathrm{ft}$. tall panel types cut from $1 / 16^{\text {th }}$ arc segments of the $10 \mathrm{~m}$ barrel section that were loaded until buckling.

\begin{tabular}{|l|l|l|l|l|}
\hline $\begin{array}{c}\text { 3-ft x 5-ft } \\
\text { Panel I.D. }\end{array}$ & \multicolumn{1}{|c|}{$\begin{array}{c}1 / 16^{\text {th }} \text { Arc Segment } \\
\text { Panel I.D. }\end{array}$} & \multicolumn{1}{|c|}{ Facesheet Material } & \multicolumn{1}{|c|}{$\begin{array}{c}\text { Facesheet } \\
\text { Lay-up }\end{array}$} & $\begin{array}{c}\text { Core Thickness } \\
\text { (in.) }\end{array}$ \\
\hline Panel A & ${ }^{\mathrm{a}} 8000-$ CMDP & IM7/977-3 (IA) & {$\left[45^{\circ} / 90^{\circ} /-45^{\circ} / 0^{\circ}\right]_{\mathrm{S}}$} & 1.000 (curved) \\
\hline Panel B-1 & ${ }^{\mathrm{b}}$ MTP-6003 & IM7/977-3 (IA) & {$\left[60^{\circ} /-60^{\circ} / 0^{\circ}\right]_{\mathrm{S}}$} & 1.125 (flat) \\
\hline Panel B-2 & MTP-6000 & IM7/977-3 (IA) & {$\left[60^{\circ} /-60^{\circ} / 0^{\circ}\right]_{\mathrm{S}}$} & 1.125 (flat) \\
\hline Panel C & $8010-C M D P$ & T40-800b/5320-1 (OOA) & {$\left[45^{\circ} / 90^{\circ} /-45^{\circ} / 0^{\circ}\right]_{\mathrm{S}}$} & 1.000 (curved) \\
\hline Panel D & MTP-6010 & T40-800b/5320-1 (OOA) & {$\left[60^{\circ} /-60^{\circ} / 0^{\circ}\right]_{\mathrm{S}}$} & 1.125 (flat) \\
\hline
\end{tabular}

${ }^{\text {a }}$ CMDP - Composite Manufacturing Demonstration Panel

${ }^{\mathrm{b}}$ MTP - Manufacturing Test Panel.

A photograph of a test specimen with potted ends is shown in Figure 3. The potted dimensions of the panels are shown in Figure 4. In addition to the overall dimensions, Figure 4a shows the relative position of the core splice with respect to the panel ends. Note that, the location of this splice was different for each panel, and Figure 4 only shows a representative location for one of the panels (see Refs. 6-9 for exact location on each panel). For complete details on the CoEx experimental efforts, the reader is referred to Ref. 10.

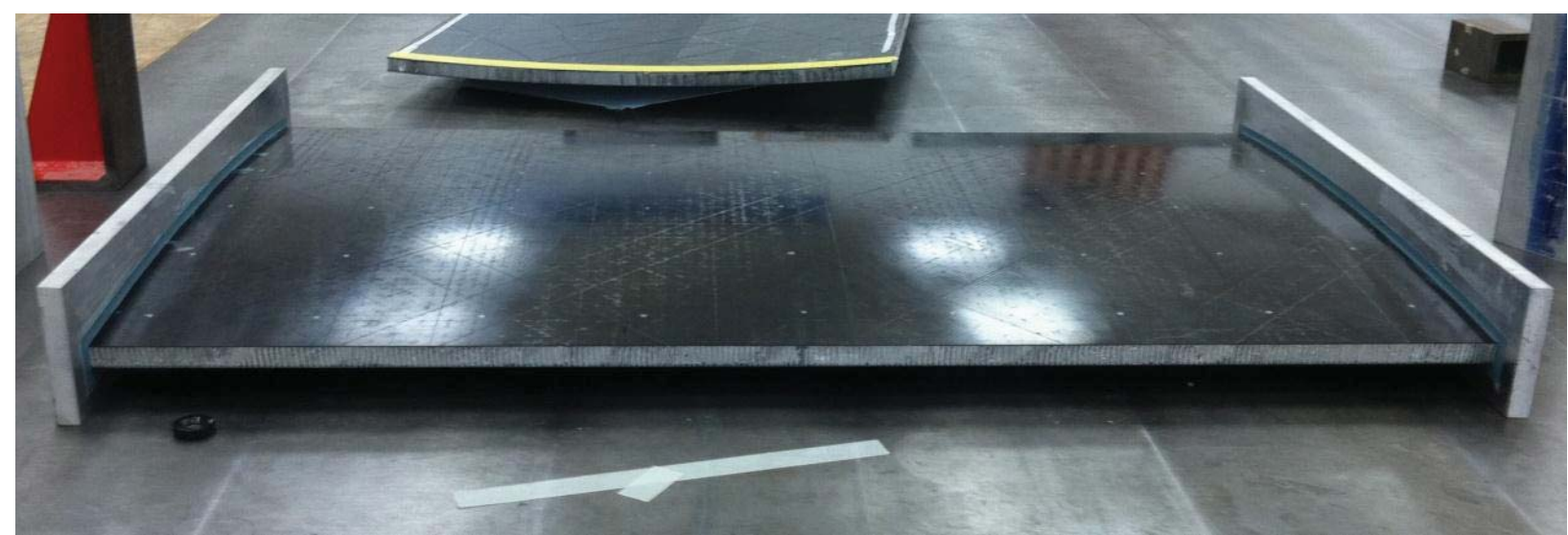

Figure 3. Test panel with potted aluminum end plates.

Upon completion of the installation of the end plates, the panels were painted using a speckle pattern for photogrammetric measurements. Visual image correlation (VIC) was utilized to obtain the pre-test panel geometry (i.e., geometric imperfection data) of the MTP panels. VIC was also used during the test employed to obtain fullfield strain measurements during the tests as well as video. NDE was performed using flash thermography to obtain a baseline for post-test comparison. In addition, strain gages were affixed to the inner diameter (I.D. or IML) and outer diameter (O.D. or OML) surfaces of the panels, as shown in Figure 4b. The even numbered gages were located on the I.D. while the odd numbered gages were located on the O.D. These gages were monitored and the strains were recorded during loading of the panel. The panels were tested at the LaRC in a servo-hydraulic test frame. The panels were secured between two loading platens, with the bottom loading platen being fixed and the top platen allowed to move in the y-direction. The panels were loaded in compression until buckling occurred under displacement control in a servo-hydraulic test rig. Additional instrumentation included three direct-current displacement transducers (DCDTs) used to measure the global, axial deformation of the panels, and a load cell attached to the load platen to measure the applied loads. Also, out-of-plane measurements were recorded at two points along the horizontal center. 


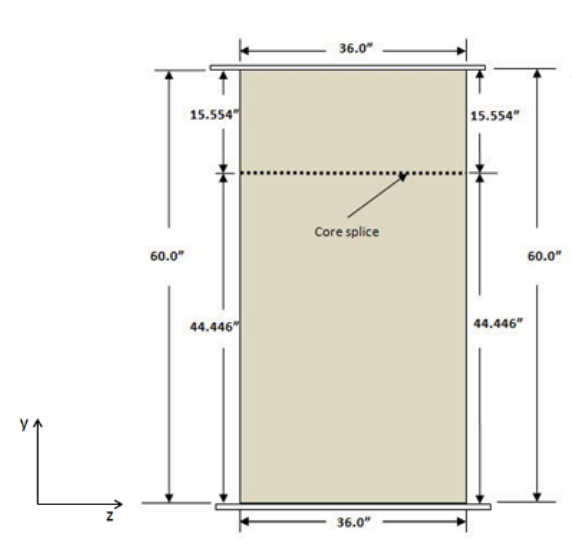

a) Core splice location.
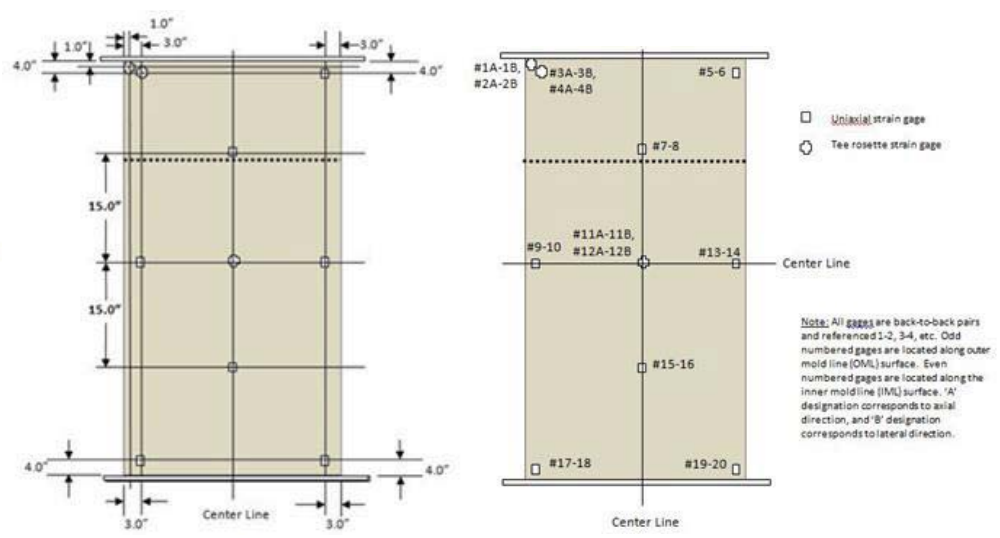

b) Strain gage locations.

Figure 4. Potted specimen dimensions with core splice and strain gage locations. Note that the core splice location was located differently for each panel. The location shown is only representative of one of the panels. The position of the core splices are also shown relative to the inside surface of the aluminum end plates.

\section{Finite Element Model Description}

\section{III.A. Geometry and Properties}

Pre-test predictions of the buckling loads for each panel were determined using commercially available FEM software packages: MSC/NASTRAN, Abaqus and ANSYS. MSC/NASTRAN and Abaqus were used for the 2-D shell models, and both provided equivalent results. Figure 5 shows the 2-D test panel geometry used in the FE models. The panels were modeled as 60.00 in. tall (section between the aluminum end plates) and $35.60 \mathrm{in}$. along the arc (35.55 in. along the chord) using two-dimensional (2D) layered shell elements (QUAD elements in MSC/NASTRAN and S4R elements in Abaqus). The shell models were offset so that the geometry corresponded to the OML. The $1.0 \mathrm{in}$. sections of the panels on the top and bottom that were supported in the potting material were not modeled. The element size was $1.00 \mathrm{in}$. by $0.97 \mathrm{in}$., and the models were comprised of 2257 nodes and 2160 elements. All three displacements and all three rotations were fixed along the bottom edge of the panels. The same boundary condition was applied to the top edges, except a displacement was applied in the negative y-direction.

The dimensions of the 3-D ANSYS model are shown in Figure 6, along with the finte element mesh, and boundary conditions. In the 3$\mathrm{D}$ model, the 1.0 in thick end fixtures are modeled explicitly (with dimensions given in Figure 2). The facesheets were modeled using zero-thickness shell elements (SHELL281), whereas the honeyomb core, aluminum end fixture, and potting compound were modeled using finite-thickness, 3-D, solid-shell elements (SOLSH190).

The elastic properties and allowables (used in strength analysis) for IM7/977-3 and T40-800b/5320-1 were obtained from the Orion materials database, and are not shown as they are ITAR restricted ${ }^{11}$. The aluminum honeycomb properties were obtained from the database included with the commercially available structural sizing software, HyperSizer $^{12}$, and are presented in Table 2. The in-plane normal and shear stiffnesses were reduced from $75.0 \mathrm{ksi}$ to $1.00 \mathrm{E}-7 \mathrm{ksi}$ since inplane load carrying capability of the honeycomb is typically neglected in honeycomb sandwich panel analysis. For the 3-D ANSYS model, the honeycomb properties (see Table 2) were obtained from

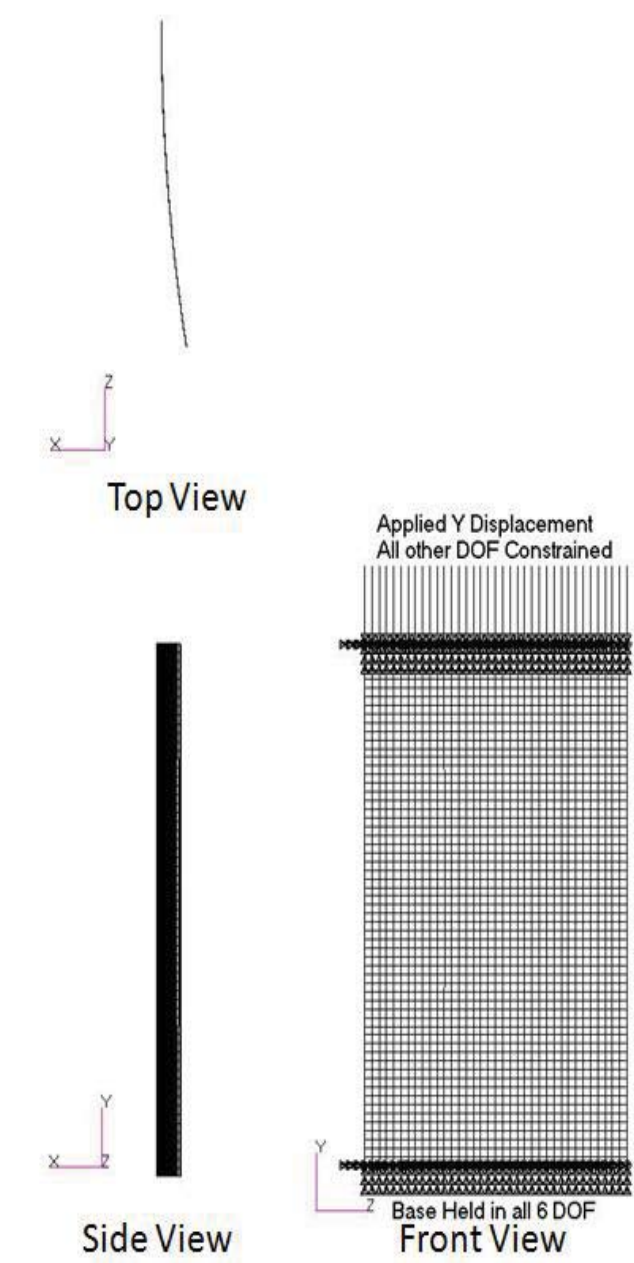

Figure 5. 2-D Panel geometry with boundary conditions. 
commercially available literature (Hexcel). Unlike the HyperSizer properties, the honeycomb in-plane longitudinal and transverse moduli $\left(\mathrm{E}_{1}\right.$ and $\left.\mathrm{E}_{2}\right)$ were kept at $21.28 \mathrm{psi}$, and the in-plane shear modulus $\left(\mathrm{G}_{12}\right)$ was kept at 5.32 psi in the ANSYS models. The honeycomb normal (out-of-plane) modulus $\left(\mathrm{E}_{3}\right)$ was also kept at $75 \mathrm{ksi}$. The elastic properties for the "UNISORB" V-100 potting compound are given in Table 3.

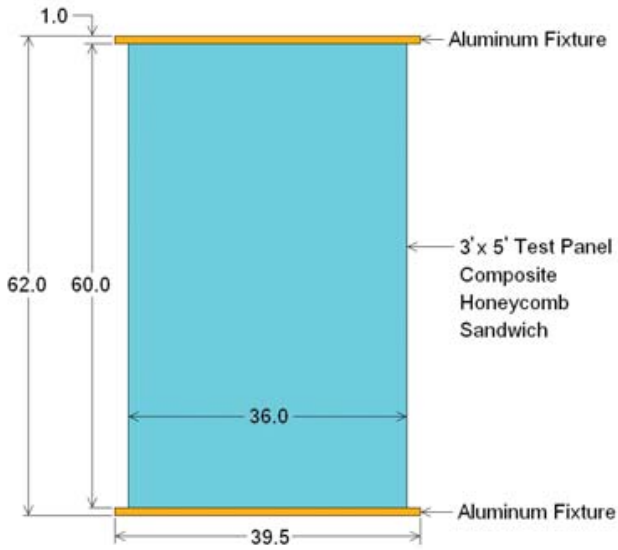

a) Dimensions.

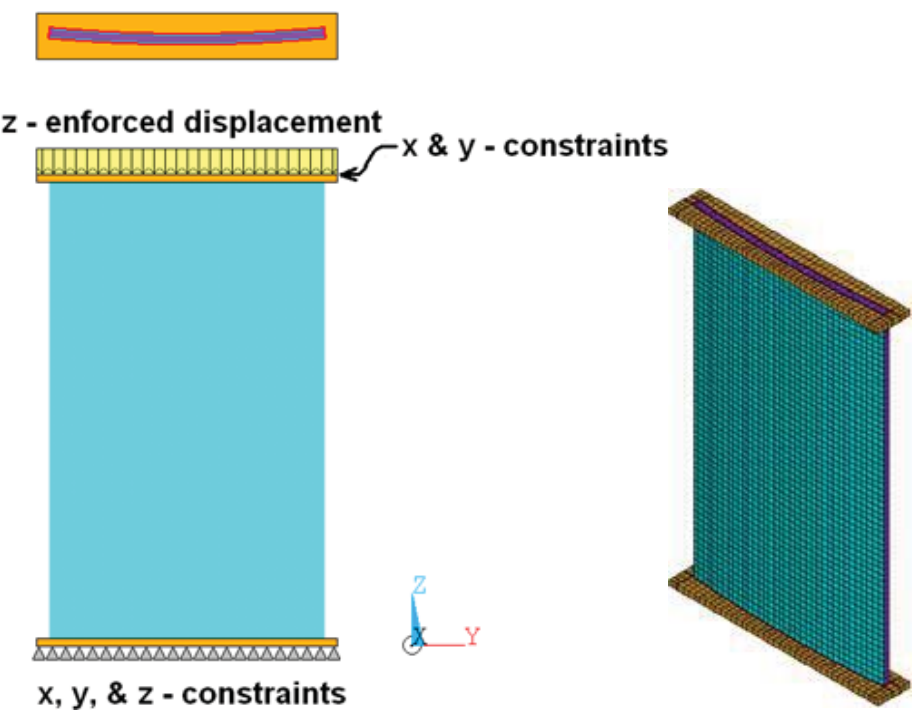

b) Boundary Conditions.

c) Mesh.

Figure 6. Details of 3-D ANSYS finite element model of panel, including loading fixtures.

Table 2. Aluminum honeycomb material properties, 3.1 pef, 1/8"-50520.0007.

\begin{tabular}{|c|c|c|c|}
\hline Property, Units & Value 2-D/3-D & Property & Value 2-D/3-D \\
\hline $\mathrm{E}_{1}, \mathrm{psi}$ & $1.0 \mathrm{E}-4 / 21.28$ & $\mathrm{~F}_{\mathrm{t} 1}, \mathrm{ksi}$ & $0.20 / 0.215$ \\
\hline $\mathrm{E}_{2}, \mathrm{psi}$ & $1.0 \mathrm{E}-4 / 21.28$ & $\mathrm{~F}_{\mathrm{cl}}, \mathrm{ksi}$ & $0.20 / 0.215$ \\
\hline $\mathrm{E}_{3}, \mathrm{ksi}$ & N.A./75 & $\mathrm{F}_{\mathrm{t} 2}, \mathrm{ksi}$ & $0.20 / 0.215$ \\
\hline$v_{12}$ & $0.333 / 0.333$ & $\mathrm{~F}_{\mathrm{c} 2}, \mathrm{ksi}$ & $0.20 / 0.215$ \\
\hline$v_{23}$ & N.A./1.0E-5 & $\mathrm{F}_{\mathrm{t} 3}, \mathrm{ksi}$ & N.A./0.13 \\
\hline$v_{13}$ & N.A./1.0E-5 & $\mathrm{F}_{\mathrm{c} 3}, \mathrm{ksi}$ & N.A./0.3 \\
\hline $\mathrm{G}_{12}, \mathrm{psi}$ & $1.00 \mathrm{E}-4 / 5.32$ & $\mathrm{~F}_{\mathrm{s} 12}, \mathrm{ksi}$ & $0.09 / 0.09$ \\
\hline $\mathrm{G}_{13}, \mathrm{ksi}$ & N.A./45.0 & $\mathrm{F}_{\mathrm{s} 13}, \mathrm{ksi}$ & $0.09 / 0.09$ \\
\hline $\mathrm{G}_{23}, \mathrm{ksi}$ & N.A./22.0 & $\mathrm{F}_{\mathrm{s} 23}, \mathrm{ksi}$ & $0.09 / 0.09$ \\
\hline$\rho, \mathrm{pcf}$ & $3.10 / 3.10$ & & \\
\hline \multicolumn{4}{|r}{} \\
\end{tabular}

Table 3. "UNISORB"

V-100 properties.

\begin{tabular}{|c|c|}
\hline$\frac{\text { Property, }}{\underline{\text { Units }}}$ & $\underline{\text { Value }}$ \\
\hline $\mathrm{E}, \mathrm{ksi}$ & 436 \\
\hline $\mathrm{v}$ & 0.35 \\
\hline
\end{tabular}

\section{III.B. Finite Element Solutions}

To arrive at the baseline buckling failure predictions, linear eigenvalue buckling analyses were performed in MSC/NASTRAN (Sol 105) for the 2-D model and ANSYS for the 3-D model. These preliminary analyses were completed for two reasons. First, the analyses provided reasonable estimates of what the non-linear analyses should predict as the panel buckling loads with an efficient, quick turnaround. Second, this is the typical method of calculating buckling loads for flight structures, and it is informative to compare the results to the experimental buckling loads and the buckling loads obtained from higher-fidelity models.

In addition, to improve numerical predictions, it was also pertinent to predict which direction (towards the I.D. or O.D.) the panels would buckle as a DCDT was to be placed to measure the out-of plane displacement of the panels and severe displacement in the unexpected direction would damage the gage. The eigenvectors obtained from an eigenvalue analysis are in an arbitrary direction and do not indicate the direction the panels would buckle. Therefore, geometrically non-linear static analyses were performed in MSC/NASTRAN (Sol 106) and Abaqus (NLGEOM) for the 2-D model, and ANSYS, for the 3-D model, to arrive at more accurate buckling loads and 
determine the direction of buckling correctly. A summary of the different FEA software/solvers/solutions is given in Table 4.

Table 4. Summary of analysis tools used to predict buckling response of sandwich panels.

\begin{tabular}{|c|c|c|c|}
\hline Software & Solution & Description & Imperfection Seeding \\
\hline MSC/NASTRAN & 105 & 2-D Linear eigenvalue solution & Approximated bow \\
\hline MSC/NASTRAN & 106 & 2-D Static solution with nonlinear geometry & Approximated bow \\
\hline Abaqus & $\begin{array}{c}\text { Static, } \\
\text { NLGEOM }\end{array}$ & 2-D Static solution with nonlinear geometry & Approximated bow \\
\hline ANSYS & $\begin{array}{c}\text { Static, } \\
\text { NLGEOM }\end{array}$ & $\begin{array}{c}\text { 3-D Static solution with load increments } \\
\text { and nonlinear geometry }\end{array}$ & $\begin{array}{c}\text { Scaled mode shapes \& } \\
\text { Approximated bow }\end{array}$ \\
\hline
\end{tabular}

\section{III.C. Imperfection Seeding}

FEA simulations of progressive collapse incorporating geometric non-linearities are extremely sensitive to the geometric imperfections in the panel ${ }^{13-19}$. Thus, it was desired to use some measure of the actual imperfections of the panels and include them in the models. Preliminary photogrammetry data of the panel showed that the bag side (I.D.) surfaces contained some initial imperfections that were biased towards the I.D. On the O.D., or the tool side, the surface imperfections were sinusoidal in nature. Herein, these surface imperfections are referred to as the bow shapes of the panels.

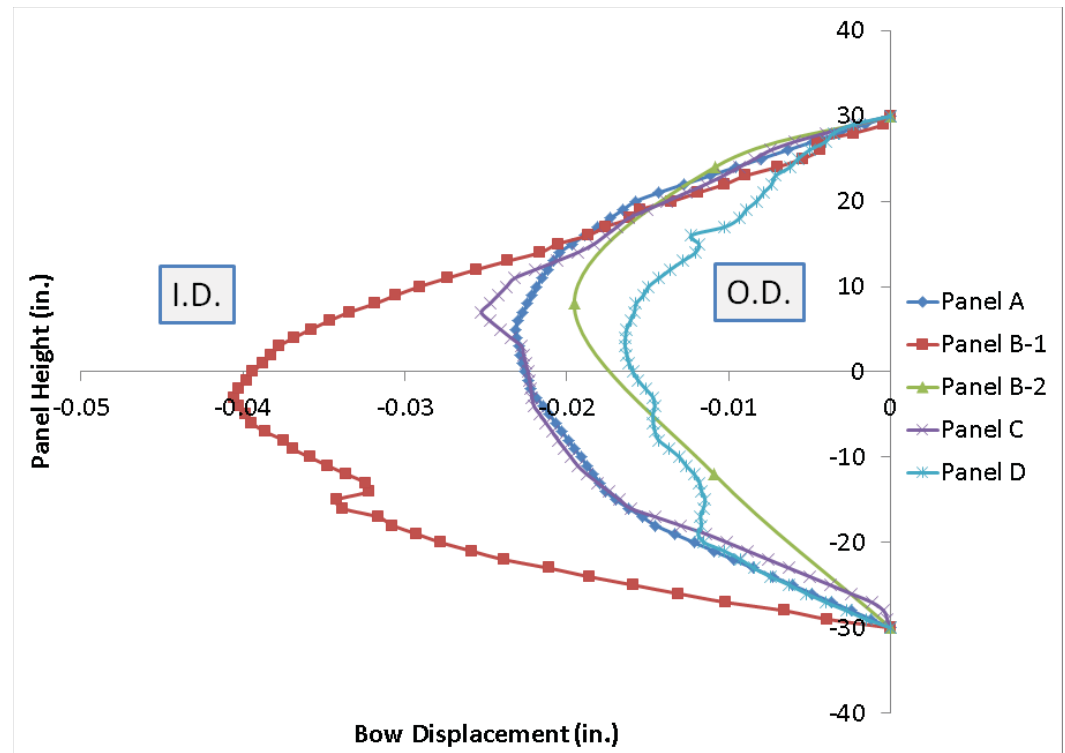

Figure 7. Geometric imperfection (bow) deflection data used to generate 2-D FEA models.
In the 2-D progressive collapse analyses, the bow data from the bag side of the panels was used to incorporate geometric imperfections into the model. Figure 7 shows the imperfection, or bow, data used in each 2-D model. This data represents the out-of-plane displacement (x-axis, see Figure 6) along a vertical line spanning the height of the panel. All five panels exhibited geometric deflections towards the I.D., opposite of the major curvature of the panel. To create the 2-D panel geometry, the bow geometry was swept along an arc of radius $198 \mathrm{in}$. and 10.272 degrees, providing a uniform tangential panel cross section. Realistically, the cross section of the panel varies in the circumferential direction, but it was assumed that the imperfect, but uniform, cross section used in the numerical model is sufficient to capture the primary effects of the geometric imperfections in the panel.

The data presented in Figure 7 represents the processed form of imperfection measurements taken from the test articles. For the CDMP panels (Panels A and C), the imperfections were measured vertically from the top of the panel to the bottom of the panel at the horizontal center using a laser track system. VIC data was used to obtain the full field out-of-plane displacement data for the I.D. faces of the MTP panels (Panels, B-1, B-2, and D). The displacement data, along the vertical height, was average circumferentially. The raw (CDMP), or averaged (MTP), photogrammetry data was then rotated such that both the top and bottom had an out-of-plane bow displacement of $0.0 \mathrm{in}$. The data was then scaled (60.0 in. / total height of photogrammetry data) so that it covered the full $60.0 \mathrm{in}$. of the panel. The raw data for Panel A contained a significant amount of noise, so a smooth interpolation of that data was used to generate the model (shown in Figure 7). The averaged and scaled data for Panel B-2 yielded a numerical result that did not correlate with the expected panel buckling direction, and it was deemed that the data contained some erroneous scatter, especially near the bottom of the panel were the data shows imperfection deflection towards the O.D. The Panel B-2 imperfection data was then approximated with a spline, shown in Figure 7 and used to create the model geometry. Panels B-1, C, and D did not use approximations of the processed data.

American Institute of Aeronautics and Astronautics 
The data in Figure 7 was also used to produce the 3-D ANSYS models by seeding the front and back faces of the model with the imperfections, such that the horizontal cross-section did not vary and contained a uniform thickness along the vertical direction. This level of imperfection did not introduce enough bias into the 3-D model, and it did not buckle under static loading. A common technique was utilized to introduced further imperfections into the model by seeding the geometry with the scaled eigenvectors obtained from a linear eigenvalue analysis. The sum of first 10 mode shapes, shown in Figure 8, where used to perturb the geometry. The eigenmodes were scaled by a factor of -0.02 in., which is on the order of the manufacturing tolerances and the measured deflection data. A negative scaling factor was used to ensure the imperfection bias was towards the I.D., as observed experimentally. An amplified plot of the imperfect geometry of the 3-D ANSYS model is shown in Figure 9. The different seeding techniques used in the various models are summarized in Table 4.
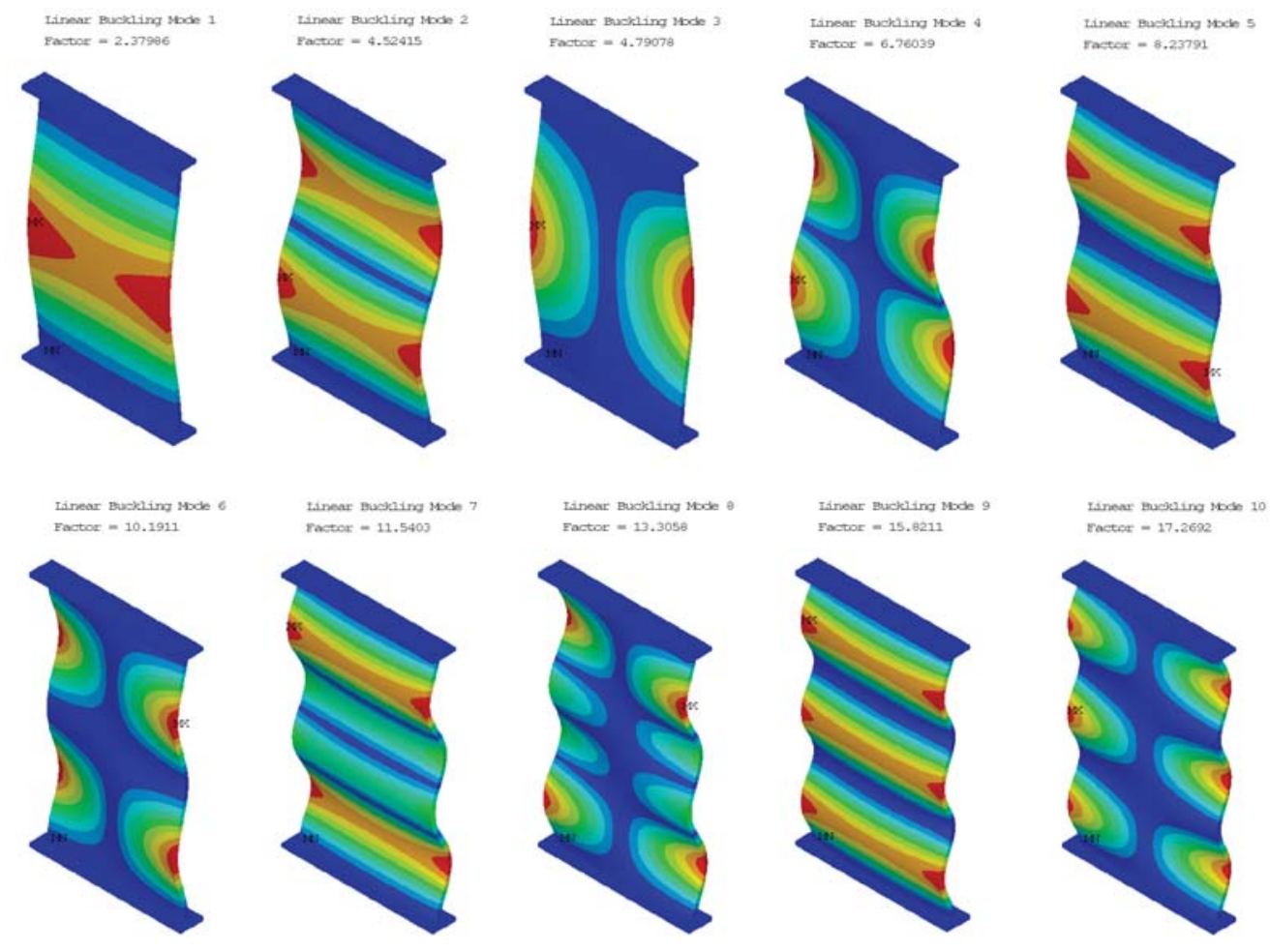

Figure 8. The first 10 linear buckling mode shapes for the 3-D ANSYS FEA model.
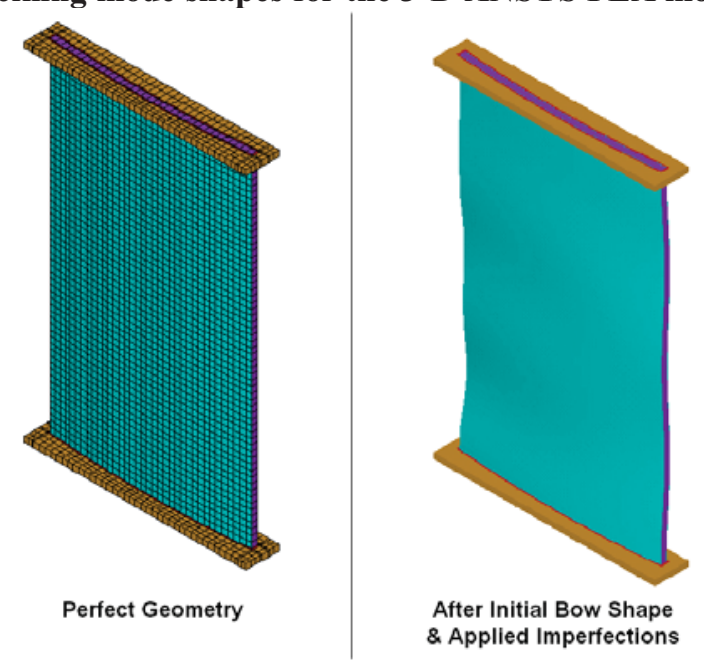

Figure 9. 3-D ANSYS FEA model with the applied initial bowed shape and geometric imperfections (exaggerated). 


\section{Results and Discussion}

The method shown in Figure 10 was used to determine the experimental and non-linear, numerical buckling loads ${ }^{20}$. This method utilizes global load versus local strain gage data (axial strain) to mark the onset of buckling. In Figure 10, a vertical tangent line intersects the load-strain curve at a local strain where the local strain increment reverses which is designated the local buckling strain. The load corresponding to that local strain is designated the buckling load. It should be noted that the buckling strain, and hence buckling load, can only be determined at monitored locations and therefore can actually be lower than the lowest measured value. Thus, the postulated buckling load is somewhat subjective and based upon the location where the strains are being monitored for reversal. Therefore there is a range of buckling loads for the experiment and non-linear FEA simulations. However, test data for Gages 9 and 10 consistently exhibited strain reversal at the lowest applied edge

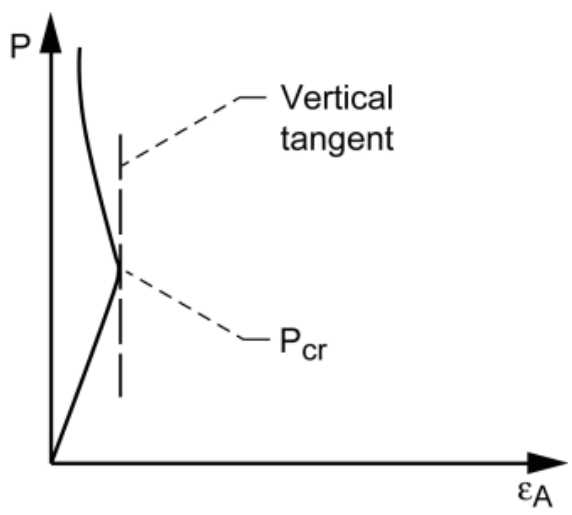

Figure 10. Method for determining buckling load ${ }^{20}$. loads, for all panels.

The buckling loads obtained from monitoring the different gages were averaged to obtain the experimental buckling loads and are tabulated in Table 5 along with the standard deviation. There is a maximum $13.3 \%$ variation in the buckling loads among the panels and the largest discrepancy is between Panel C and D which are both OOA panels. It appears that the 8-ply configuration slightly out-performs the 6-ply configuration, regardless of the material system. For the 6-ply configuration, the IA system demonstrates a higher buckling resistance than the OOA. However, since the buckling of these curved panels is so sensitive to imperfections, no solid conclusions can be made from such a small sample size.

Table 5. Buckling loads obtained from experiment.

\begin{tabular}{|l|r|r|}
\hline Panel & Average Buckling Load (lbs.) & Standard Deviation (lbs.) \\
\hline A (IA) & 73,213 & 750 \\
\hline B-1 (IA) & 70,907 & 421 \\
\hline B-2 (IA) & 69,172 & 724 \\
\hline C (OOA) & 73,468 & 1,198 \\
\hline D (OOA) & 64,848 & 582 \\
\hline
\end{tabular}

\section{IV.A. Linear Buckling Analysis}

Linear buckling analyses were performed using MSC/NASTRAN Sol 105 for the 2-D finite element model and ANASYS for the 3-D model. These eigenvalue solutions are compared to the experimental buckling loads in Table 6. All eigenvalue buckling load predictions were $3-24 \%$ above the experimental buckling loads. The maximum error was $24 \%$ and corresponded to Panel D, which showed the largest deviation in buckling load with respect to the other panel buckling loads, experimentally. The buckling loads predicted with the 3-D model are comparable to the 2-D buckling loads and are slightly closer to the experiment. A maximum reduction in error of 3.4\% was obtained with the 3-D analysis for Panel B-2. The corresponding eigenvector plots for the 2-D and 3-D analyses are displayed in Figure 11. All ten analyses displayed similar eigenmodes. Thus, for brevity, only two representative plots for a single panel are shown. The exhibited eigenmode does not correspond to cylindrical buckling. Thus, any conclusions made from this work cannot be directly applied to cylindrical buckling, but can be utilized for general, imperfection sensitive buckling analyses. Although, it is possible to scale the size of the panel and obtain an eigenmode representative of cylindrical buckling from an arc segment ${ }^{21}$.

Table 6. Buckling loads obtained from linear eigenvalue analysis.

\begin{tabular}{|l|r|r|r|r|}
\hline Panel & 2-D Buckling Load (lbs.) & Error (\%) & 3-D Buckling Load (lbs.) & Error (\%) \\
\hline A & 80,912 & 10.5 & 79,471 & 8.6 \\
\hline B-1 & 74,245 & 4.7 & 72,928 & 2.8 \\
\hline B-2 & 75,248 & 8.8 & 72,884 & 5.4 \\
\hline C & 82,318 & 12.0 & 82,319 & 12.0 \\
\hline D & 80,283 & 23.8 & 79,471 & 22.5 \\
\hline
\end{tabular}

9

American Institute of Aeronautics and Astronautics 


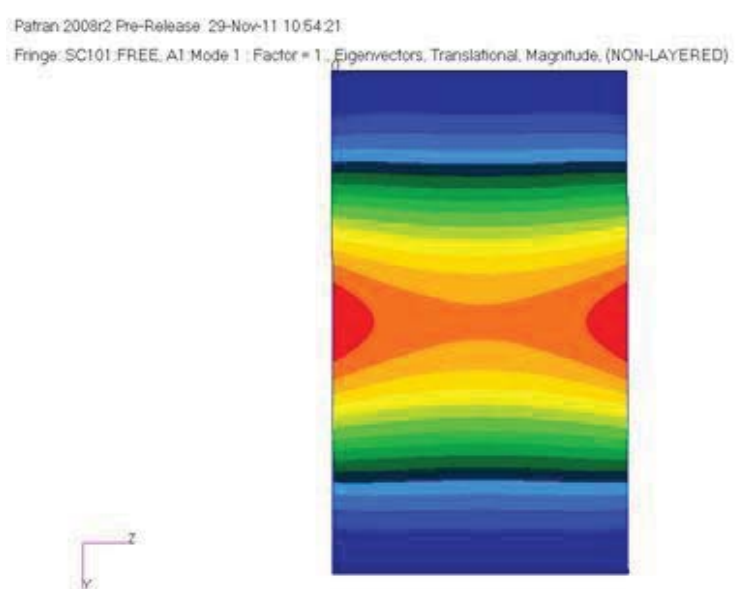

a) 2-D.

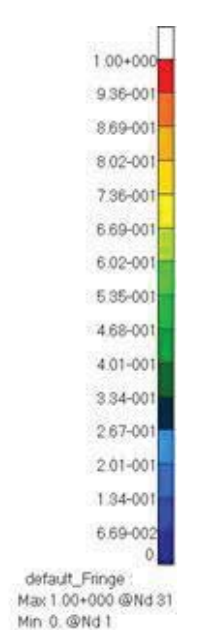

Figure 11. Plot of eigenvectors obtained from linear eigenvalue analyses.

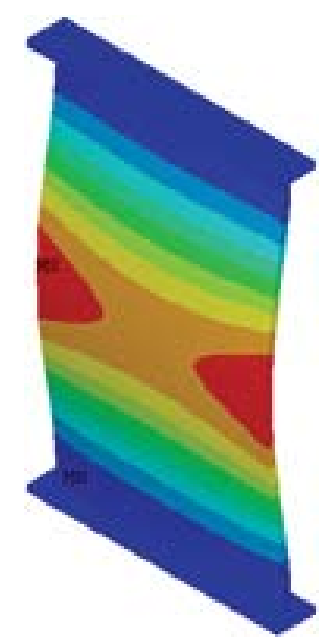

b) 3-D.

\section{IV.B. Geometrically Non-linear Progressive Collapse (Buckling) Analysis}

\section{IV.B.1 Quantitative results}

To improve the pretest predictions of the buckling loads, geometrically non-linear, 2-D, progressive collapse analyses were executed using MSC/NASTRAN Sol 106. For verification, several additional analyses were completed, including static non-linear ANSYS, and geometrically non-linear Abaqus/Standard. All three tools provided very similar results for the 2-D model; thus, only the MSC/NASTRAN results will be presented. Furthermore, 3-D progressive collapse simulations were executed using ANSYS.

Figure 12 shows the load versus deflection curves obtained for the five different panels from experiment, 2-D non-linear analysis, and 3-D non-linear analysis. The deflection from the experiment was obtained by averaging the measurements from three DCDTs, and the reaction load was measured using a load cell. Figure 12 shows that the predicted panel stiffnesses, buckling loads and post-buckling behavior match reasonably well with experiment. A marked difference between the 6-ply and 8-ply configurations can be observed. However, there is not a noticeable difference in performance between the two material systems (IA and OOA). Note that some of the experiments were not continued into

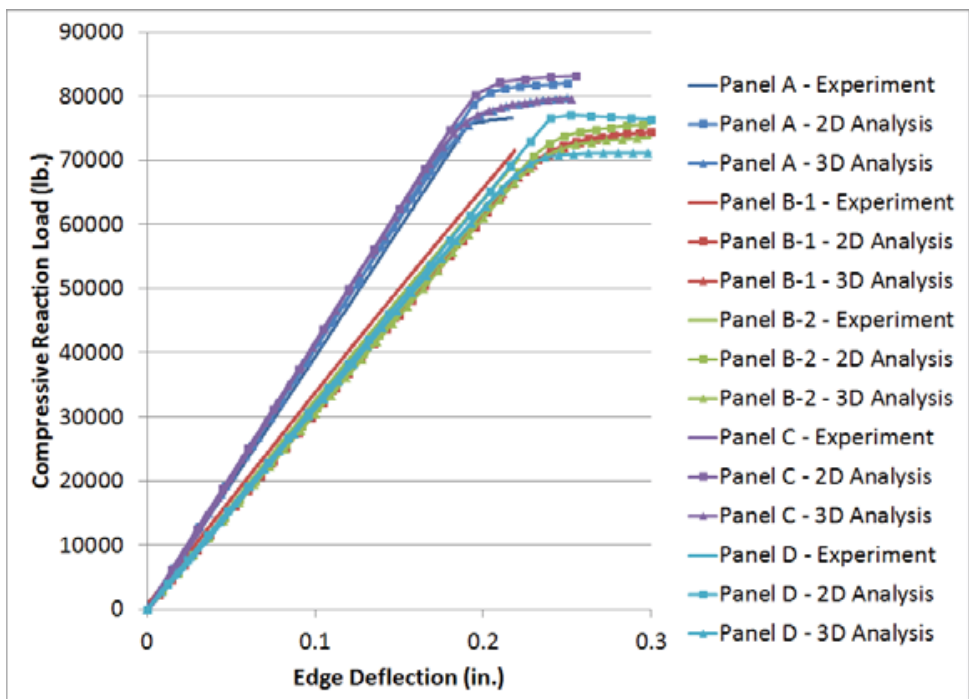

Figure 12. Load-deflection curves from experiment and non-linear analyses. the post-buckled regime, but rather the tests were stopped to prevent any damage to the panel so that they may be used for subsequent testing.

The slope of the load-deflection curves, in the linear (pre-buckling) regime, for each panel are compared in Figure 13. For the experiment, the average result obtained from the three different DCDTs is used, the error bars represent the standard deviation of the three measurements. All of the 6-ply systems exhibit the similar slopes. As do the 8-ply systems, but the slopes differ from that of the 6-ply systems, as expected. Since these slopes are a measure of the test articles stiffness, it indicates the accuracy of the material properties used in the models. There is 


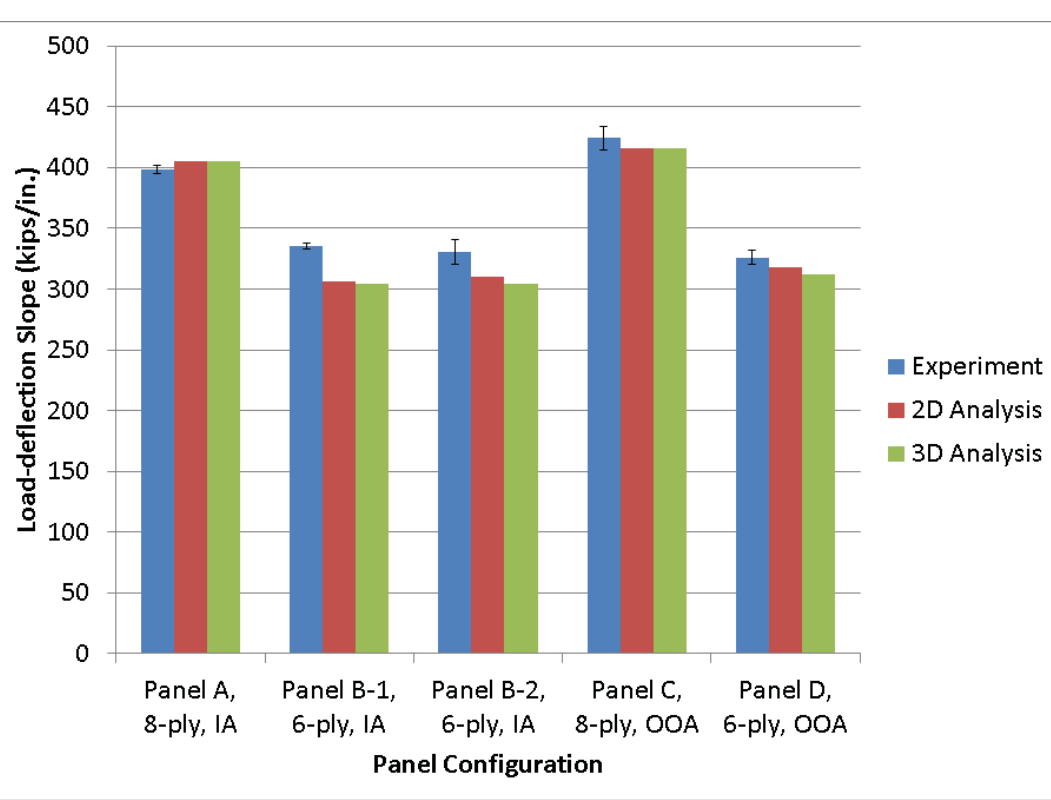

Figure 13. Slope of load-deflection curves obtained from experiment, 2-D, and 3-D non-linear analyses.

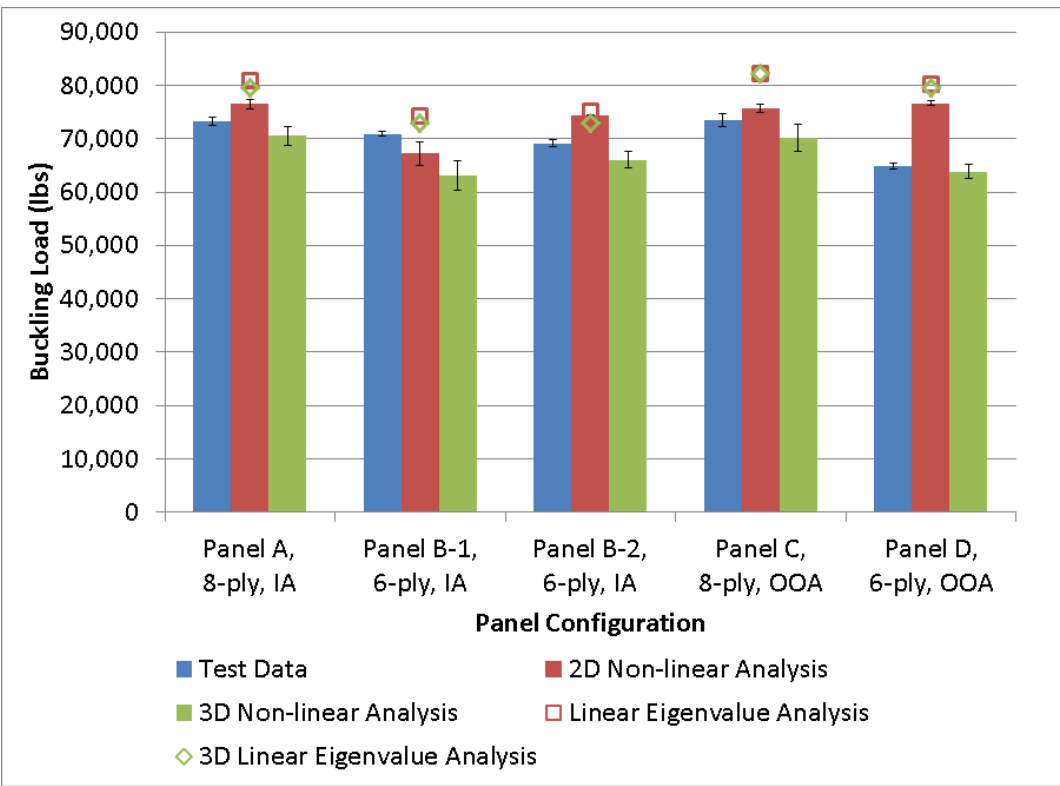

Figure 14. Experimental buckling loads and analytical predictions. minimal difference between the slopes predicted by the 2-D and 3-D analyses, demonstrating that the loadfixtures are not affecting the overall stiffness of the test specimen. There is some small discrepancy between the experimental slopes and the analytical slopes. This could be a result of slight loading eccentricity, fiber misalignment, or discrepancy in material properties. Both 8-ply systems displayed a higher stiffness than the 6-ply systems; this is consistent with the experimental and linear buckling load results.

Figure 14 shows the buckling load from all tests and analyses (this data is also summarized in Table 7). The error bars on the experimental results and the non-linear analysis show the standard deviation in the buckling loads obtained by monitoring the different gages. It can be observed that the 2-D, geometrically non-linear, progressive collapse simulations provided better predictions of the buckling loads than the 2-D linear eigenvalue analyses. However, the predictions were still non-conservative, but they were reasonable (within 19\%), except for Panel D. Predictions from the 3-D, non-linear analyses were always conservative within $11 \%$ and are improved from the 3-D linear eigenvalue analyses. In most cases, except for Panel B-1, the buckling load predictions from the 3-D linear eigenvalue analyses are the most accurate. It is difficult to assess a trend, or make any definitive statements, from these results because both non-linear methods utilized different imperfection techniques and the results appear to be very imperfection sensitive. However, all buckling load predictions are well within 65\% (the shell buckling knockdown factor) of the experimental results.

Table 7. Buckling loads predicted by non-linear analyses.

\begin{tabular}{|l|r|r|r|r|}
\hline Panel & 2-D Buckling Load (lb.) & Error (\%) & 3-D Buckling Load (lb.) & Error (\%) \\
\hline A & 76,524 & 4.5 & 70,582 & -3.6 \\
\hline B-1 & 67,238 & -5.2 & 63,087 & -11.0 \\
\hline B-2 & 74,336 & 7.8 & 66,107 & -4.4 \\
\hline C & 75,661 & 3.0 & 70,216 & -4.4 \\
\hline D & 76,660 & 18.2 & 63,795 & -1.6 \\
\hline
\end{tabular}

American Institute of Aeronautics and Astronautics 


\section{IV.B.2 Qualitative Results}

An additional capability afforded by the non-linear analyses, that is not available with the linear analysis, is the ability to predict the direction in buckling. All five panels deflected towards the I.D., away from the primary direction of curvature (O.D.). The direction can be inferred from the strain reversal in any of the gages. As an example, the load versus strain at gages 9 and 10, for Panel A, is presented in Figure 15. The change in the sign of the strain increment indicates buckling ${ }^{20}$. The strain increment reverses at gage 10, which was placed on the I.D. Reversal of the strain increment designates that the gage is going from a axial compressive state to a state of axial tension. If the axial state is becoming tensile, then the gage must be on the outer surface of the post-buckled panel. Therefore, the panel must be buckling towards the I.D. Without the imperfection seeding, the non-linear analysis predicted panel buckling towards the O.D., but with the imperfections added, the buckling occurred towards the I.D.
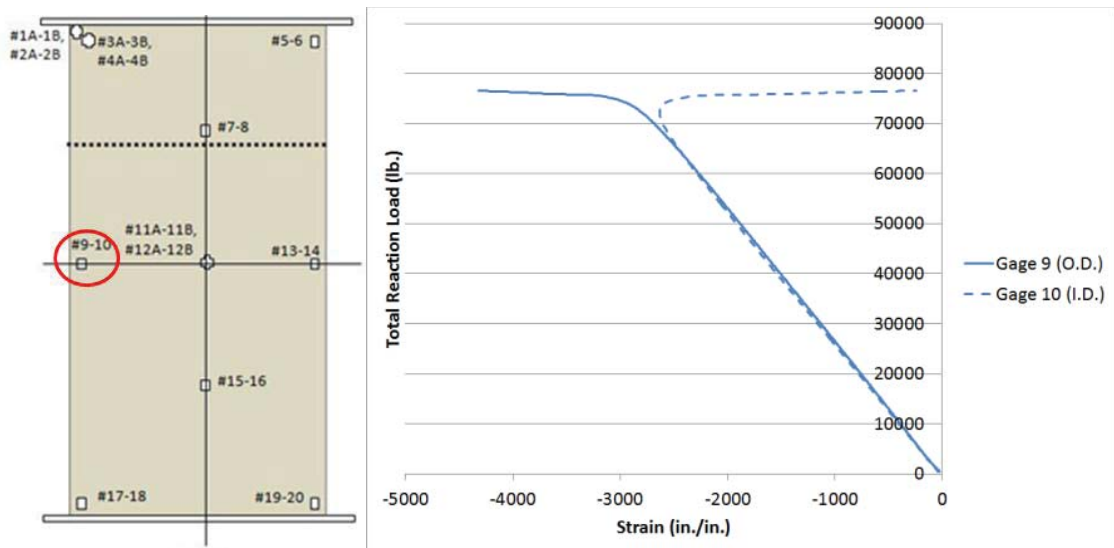

Figure 15. Total reaction load versus local gage strain. Reversal in sign of strain increment indicates buckling. Strain increment reversal on gage place on I.D. indicates buckling towards I.D.

This is shown qualitatively in Figure 16 which shows the post-buckled state for Panel A from the 2-D and 3-D non-linear analyses. The x-axis in both Figures 16a and 16b indicate the direction of the O.D., but the panels are oriented differently in the figures. Both plots show buckling towards the negative x-direction, or I.D. All 10 simulations exhibited post-buckled shapes to the first linear eigenmode, and all 10 simulations accurately predicted buckling towards the I.D. Note that, this buckling mode is not representative of the buckling of a full cylinder. However it would be possible to reproduce the cylindrical buckling mode with different panel dimensions ${ }^{21}$.

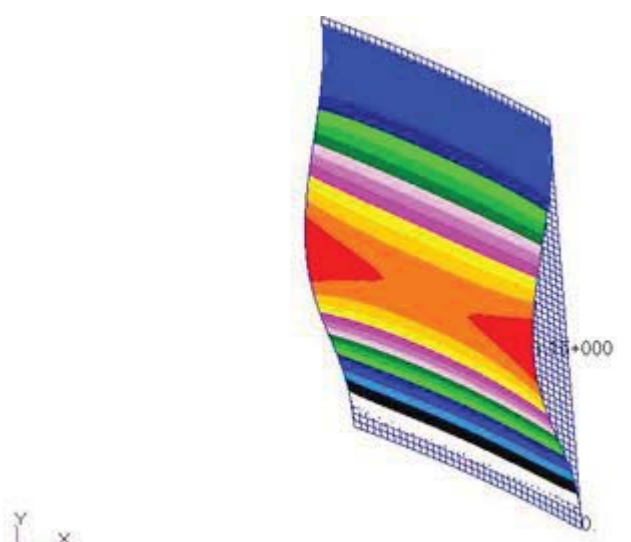

a) 2-D NASTRAN

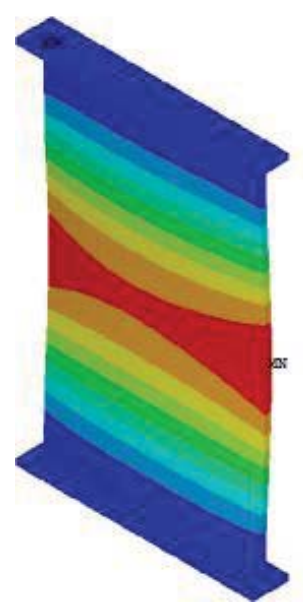

b) 3-D Abaqus

Figure 16. Post-buckling shapes determined from geometrically non-linear progressive collapse FEA. Buckling predicted towards the I.D. of the panels. 
Figure 17 and 18 show a comparison between the predicted displacement conotuors and the measured VIC displacement. All 5 panels produced similar results, so these contours (and the following strain contours) are only shown for a demonstrative panel as a qualitative comparison. Since displacement is given as a nodal quantity, and the shell models have zero thickness there is no difference in the displacement contours on the I.D. and O.D. So, only one displacement contour is presented for the analysis. However, with the test article there is a finite thickness yielding some difference in the surface contour displacement. Both the axial (y-direction) and out-of-plane (xdirection) displacement contours in the post-buckled state predict using the non-linear NASTRAN FEA agree with the VIC data. The out-of-plane displacement, shown in Figure 18, shows the buckling mode.

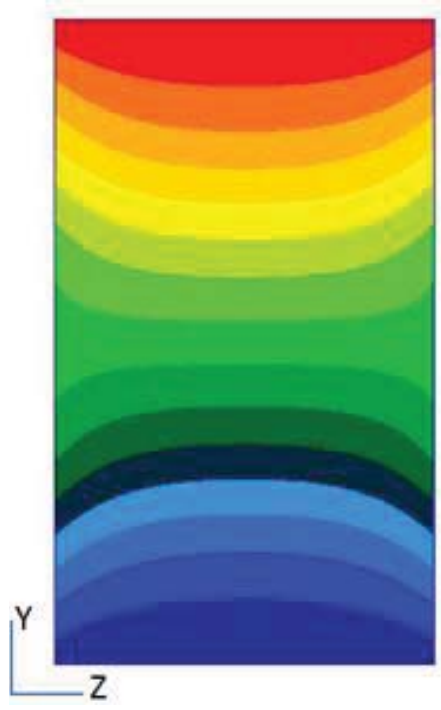

a) 2-D NASTRAN

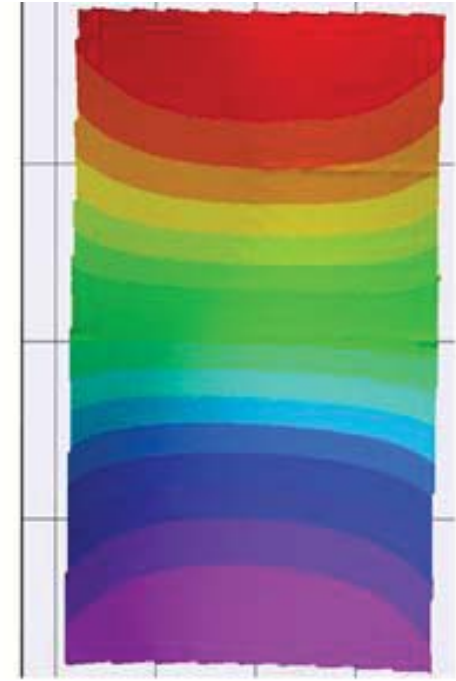

b) VIC of O.D. surface

Figure 17. Post-buckled, axial (y) displacement comparison.

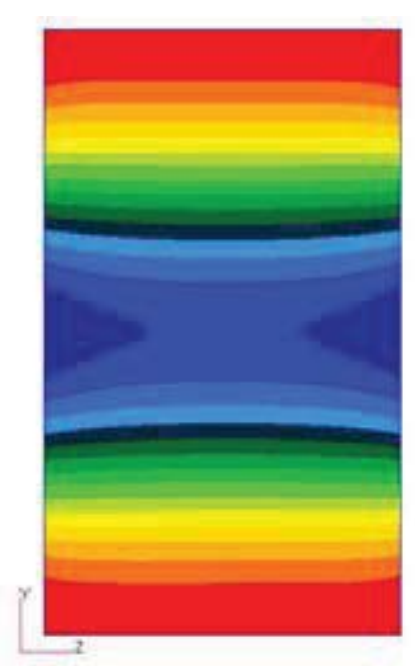

$\begin{array}{lll} & \text { a) 2-D NASTRAN } & \text { b) VIC of O.D. surface } \\ \text { Figure 18. } & \text { Post-buckled, out-of-plane (x) displacement comparison. }\end{array}$

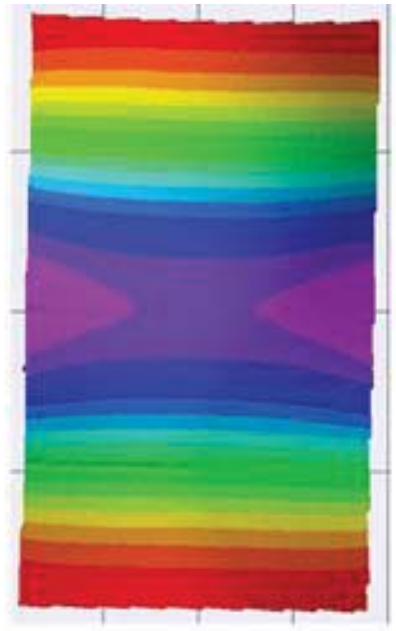

$\begin{array}{lll}\text { a) 2-D NASTRAN } & \text { b) VIC of O.D. surface } \\ \text { Figure 18. } & \text { Post-buckled, out-of-plane (x) displacement comparison. }\end{array}$

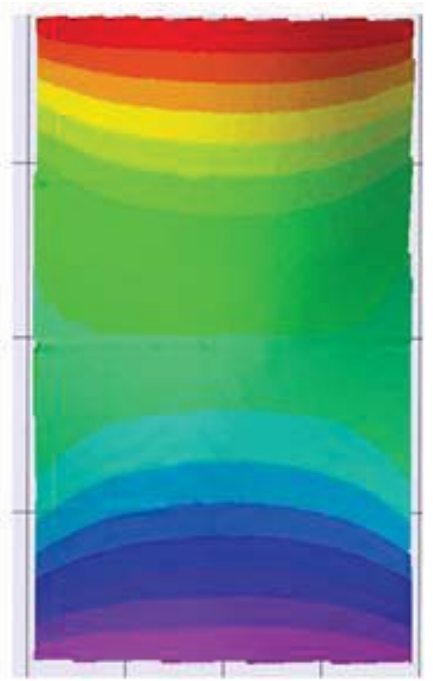

c) VIC of I.D. surface

Similar agreement is exhibited in the strain contour plots (Figures 19 and 20). Strain contours at both the I.D. and O.D. from the NASTRAN analysis are compared to analogous VIC data. Figure 19 shows very good accordance for the axial (y-direction) strain between the analysis and test for both surfaces, which display drastically different contour shapes. Similarly, the radial (z-direction) strain is predicted well by NASTRAN for both surfaces (Figure 20). The 3-D analyses also produced desirable qualitative, post-buckled contours but are omitted for conciseness. 


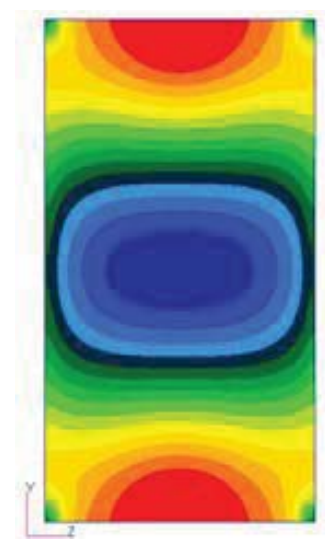

a) 2-D NASTRAN, O.D.

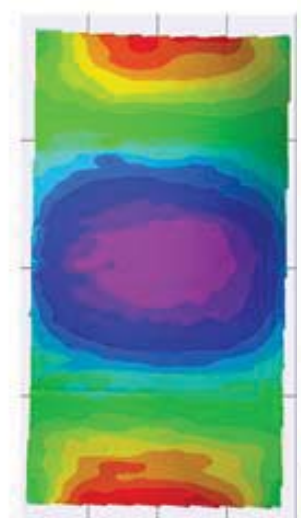

b) VIC of O.D.

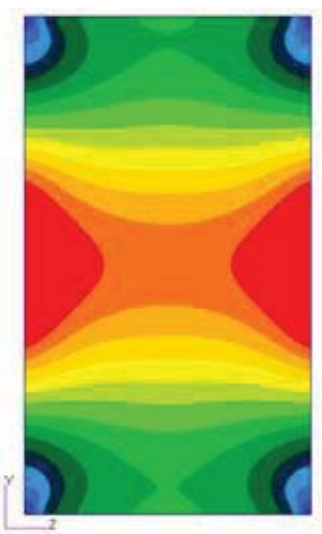

c) 2-D NASTRAN, I.D.

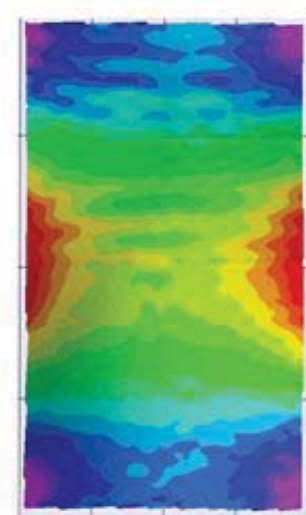

d) VIC of I.D.

Figure 19. Post-buckled, axial (y) strain comparison.

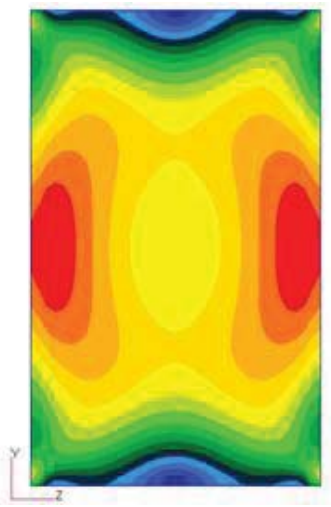

a) 2-D NASTRAN, O.D. b) VIC of O.D.

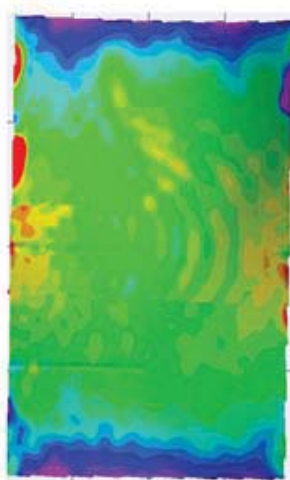

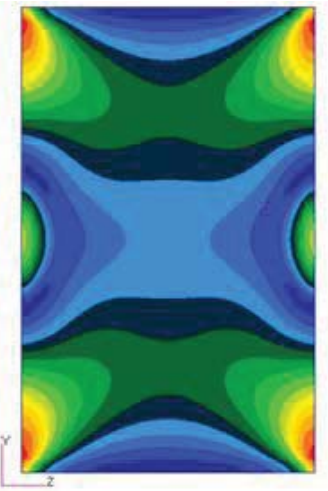

c) 2-D NASTRAN, I.D.

Figure 20. Post-buckled, radial (z) strain comparison.

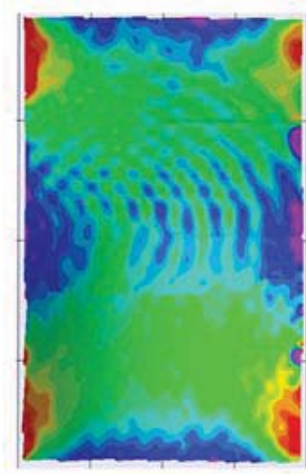

d) VIC of I.D.

\section{IV.C. Strength Analysis at Bucking Load}

In a separate linear static analyses, the panels (Panel B-2 excluded) were loaded up to the buckling loads (determined from the non-linear static analyses) using MSC/NASTRAN Sol 101. These analyses was performed to confirm that panel failure was stiffness driven (i.e., the panels would be expected to buckle before they failed in strength). The strength ratio is the local stress divided the allowable, and it incorporates one of three multiaxial failure criteria: Tsai-Wu, Tsai-Hill, Hoffman ${ }^{22}$. Table 8 shows the lowest strength ratio among the three criteria, and all facesheet plies, for each element of each panel. These strength ratios range from 2.15-2.74, well above 1 (required for failure). Figure 21 shows a typical strength ratio contour plot of the panel. The regions exhibiting the lowest strength ratios are limited to the corners of the panels, while the majority of the panels exhibited strength ratios above 3.0. Furthermore, the magnitude of the stresses near the corners is likely to be dependent on the size of the elements used in those areas, due to the presence of perfectly sharp corners in the model.

Table 8. Minimum strength ratios in panels predicted by NASTRAN Sol 101 and Hypersizer at buckling load.

\begin{tabular}{|c|c|c|c|c|c|c|}
\hline Panel & $\begin{array}{l}\text { NASTRAN } \\
\text { Strength Ratio }\end{array}$ & $\begin{array}{l}\text { Hypersizer Tsai-Wu } \\
\text { Strength Ratio }\end{array}$ & $\begin{array}{l}\text { Hypersizer MS } \\
\text { Top Facesheet } \\
\text { (Mode) }\end{array}$ & $\begin{array}{l}\text { Hypersizer MS } \\
\text { Bot. Facesheet } \\
\text { (Mode) }\end{array}$ & $\begin{array}{l}\text { Hypersizer MS } \\
\text { Core (Mode) }\end{array}$ & Eq. (2) \\
\hline $\bar{A}$ & 2.45 & 2.49 & 1.10 (wrinkling) & 1.06 (wrinkling) & $\begin{array}{l}12.82 \\
\text { (shear crimping) }\end{array}$ & 2.92 \\
\hline B-1 & 2.15 & 2.15 & 0.15 (wrinkling) & 0.17 (wrinkling) & $\begin{array}{l}16.94 \\
\text { (shear crimping) }\end{array}$ & 0.96 \\
\hline $\mathrm{C}$ & 2.74 & N.A. & N.A. & N.A. & N.A. & N.A. \\
\hline $\bar{D}$ & 2.15 & N.A. & N.A. & N.A. & N.A. & N.A. \\
\hline
\end{tabular}


Figure 21. Typical strength ratio contour plot predicted by MSC/NASTRAN Sol 101 at buckling load.

In addition to performing the strength analyses using MSC/NASTRAN Sol 101, strength analyses were performed in HyperSizer, a commercially available structural sizing and design software ${ }^{12}$, for Panels A and B-1. The honeycomb properties used in these analyses were the same as those used in the 3-D ANSYS analyses and are given in Table 2. The element forces and moments were obtained using FEA, and the honeycomb was constructed using explicit ply lay-ups. Element-based comparisons were used to ensure that worst case behavior was captured. The following modes of failure were of most interest: core crimping, core crushing, facesheet wrinkling, and facesheet dimpling, as these modes are difficult to assess using FEA alone.

The minimum margins of safety (MS) for core crimping, core crushing, facesheet wrinkling, and facesheet dimpling are tabulated in Table 8. It should be noted that the minimum strength ratios from NASTRAN and Hypersizer matched very well for Panels A and B-1, and all strength MS were positive. The minimum MS predicted by Hypersizer were activated by facesheet wrinkling (1.06 for Panel A and 0.15 for Panel B-1) at the corners of the panel. It was determined that the wrinkling equations used to produce the MS given in Table 8 were not appropriate for a honeycomb sandwich panel with laminated composite facesheets ${ }^{23}$. Therefore, wrinkling stress (sw) was assessed at 1.06 and 0.15 using the wrinkling equation for anisotropic facesheets and cellular core ${ }^{24}$, as is more appropriate for this panel.

$$
s w=\sqrt{\frac{2 t_{f} E_{c} E_{f}}{3 t_{c}\left(1-v_{f}{ }^{2}\right)}}
$$

where $t_{f}$ is the facesheet thickness, $t_{c}$ is the core thickness, $E_{f}$ is the facesheet modulus, $E_{\mathrm{c}}$ is the core modulus, and $v_{f}$ is the facesheet Poisson's ratio. To improve the accuracy the wrinkling MS, a combined loading condition was used with two compressive principal stresses ${ }^{25}$.

$$
\mathrm{MS}=\frac{1}{\sqrt{\left(\frac{\sigma_{1}}{\mathrm{sw}}\right)^{3}+\frac{\sigma_{2}}{\mathrm{sw}}}}-1
$$

where $\sigma_{1}$ and $\sigma_{2}$ are the principal stresses. Using this more appropriate method, the minimum margin of safety further increased from 1.06, 0.15 to 2.92, 0.96. Thus, it was predicted that facesheet wrinkling in the corners of the panel would not be an issue. This was further supported by experimental strain data recorded from strain gages at the corner ${ }^{6-9}$; thus, this precautionary analyses was deemed unnecessary for Panels B-2, C, and D. 


\section{Sensitivity Studies}

As discuss in the introduction, buckling of cylindrical (or curved) structures are extremely sensitive to imperfections ${ }^{1}$. Accordingly, a shell buckling knockdown factor is used to ensure a conservative solution ${ }^{2}$. Unfortunately, the knockdown factor does not account for the sensitivity of the structure to the various types of imperfections on an individual basis. This can often lead to very over-conservative designs. The results presented in Section IV show that, for this type of structure, the linear eigenvalue buckling prediction is $24 \%$ of the experimental buckling load. Furthermore, the buckling predictions can be improved to within $19 \%$ by including the imperfections and geometric non-linearity into a 2-D shell analysis or within $11 \%$ with a 3-D analysis. All of the analyses are well within the 0.65 shell buckling knockdown factor. However, safety is of the utmost important in vehicle design, and in order to enact a change in any safety factor the phenomena influencing the failure must be thoroughly understood. In this section results are presented from preliminary sensitivity studies performed to understand the sensitivity of honeycomb sandwich panel arc segments to geometric imperfections, fiber misalignment, and loading eccentricity. The results of these sensitivity studies could also be used to establish manufacturing tolerances to maximize the performance of the panels or minimize the sensitivity of the panels to those manufacturing defects.

\section{V.A Sensitivity to Geometric Imperfections}

To investigate the sensitivity of the honeycomb sandwich panel arc segments to geometric imperfections that may results from manufacturing, imperfections are deliberately introduced into the 2-D panel geometry as an arcshaped deflection, spanning the height of the panel, towards the I.D. The geometry of a pristine (no geometric imperfections) panel is created by sweeping a line (with length equal to the height of the panel) along a $10.5^{\circ}$ arc segment of the circumference of a circle (with radius of $198.0 \mathrm{in}$.). The imperfection is introduced such that the swept geometry becomes an arc (rather than a line). The endpoints of the arc coincide with the endpoints of the line used to create the pristine geometry, but the center of the arc passes through a point which is displaced towards the I.D. of the panel equal to the magnitude of the bow. The swept geometry for an imperfect panel is shown in Figure 22. In this study the magnitude of this maximum bow deflection was varied and the buckling load and direction were noted.

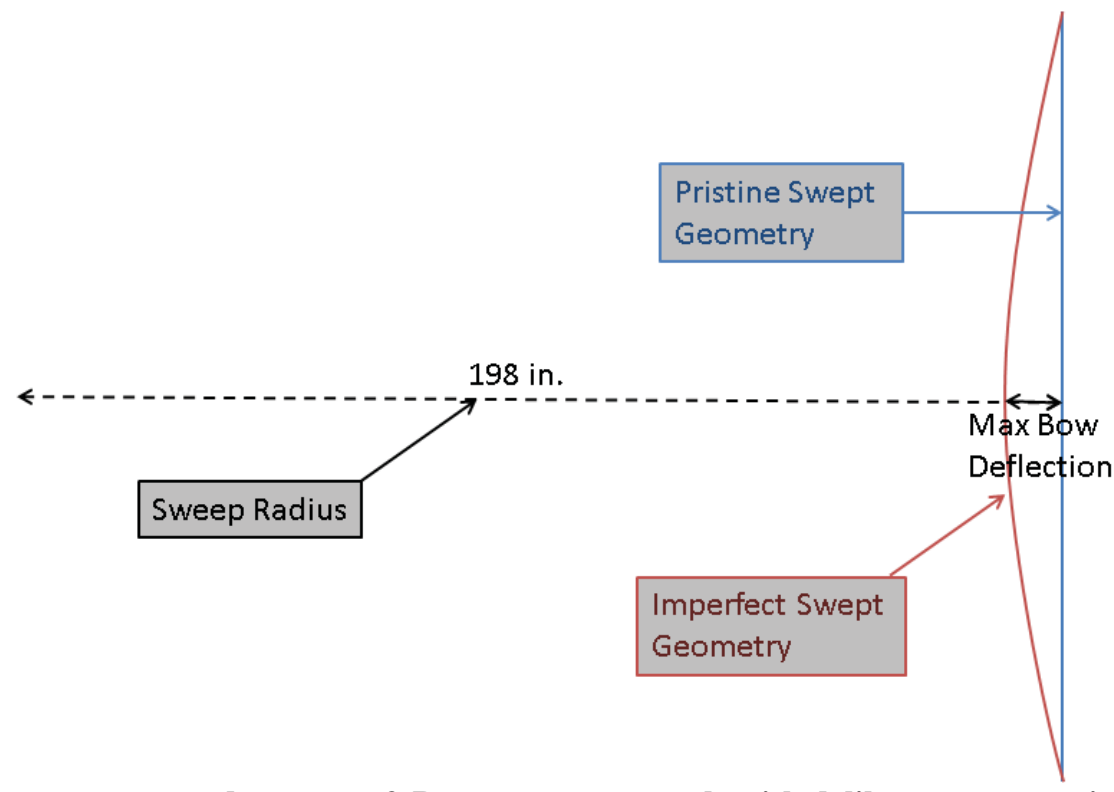

Figure 22. Swept geometry used to create 2-D arc segment panels with deliberate geometric imperfections.

This sensitivity study was performed on two configurations: 8-ply, I.A. (Panel A) and 6-ply, I.A. (Panel B-1/B2). The predicted buckling loads versus maximum bow deflections are presented in Figure 23 along with the corresponding data from the experiments and the analysis using the actual measured bow data (which was not arcshaped as the geometry used for the study, shown in Figure 22). Due to the major curvature in the panels, the buckling direction for pristine panels would be towards O.D. Any additional geometric imperfections towards the 
O.D. would simply continue to perturb the panel buckling in that same direction. If the geometric imperfections introduces panel deflection towards the I.D. then the perturbation in the geometry actually resists the buckling towards the O.D. This can be observed in Figure 23. As the bow deflection is increased from 0.0 in to 0.016 in for Panel A and 0.017 in. for Panel B-1/B-2, the buckling load continues to increase because there must be enough energy for the panel to snap-through the I.D. biased imperfections towards the O.D. However, if the imperfections towards the I.D. are increased beyond some critical value, the direction of buckling switches from towards the O.D. to towards the I.D. Now, any further increase in the imperfections towards the I.D. will reduce the buckling load.

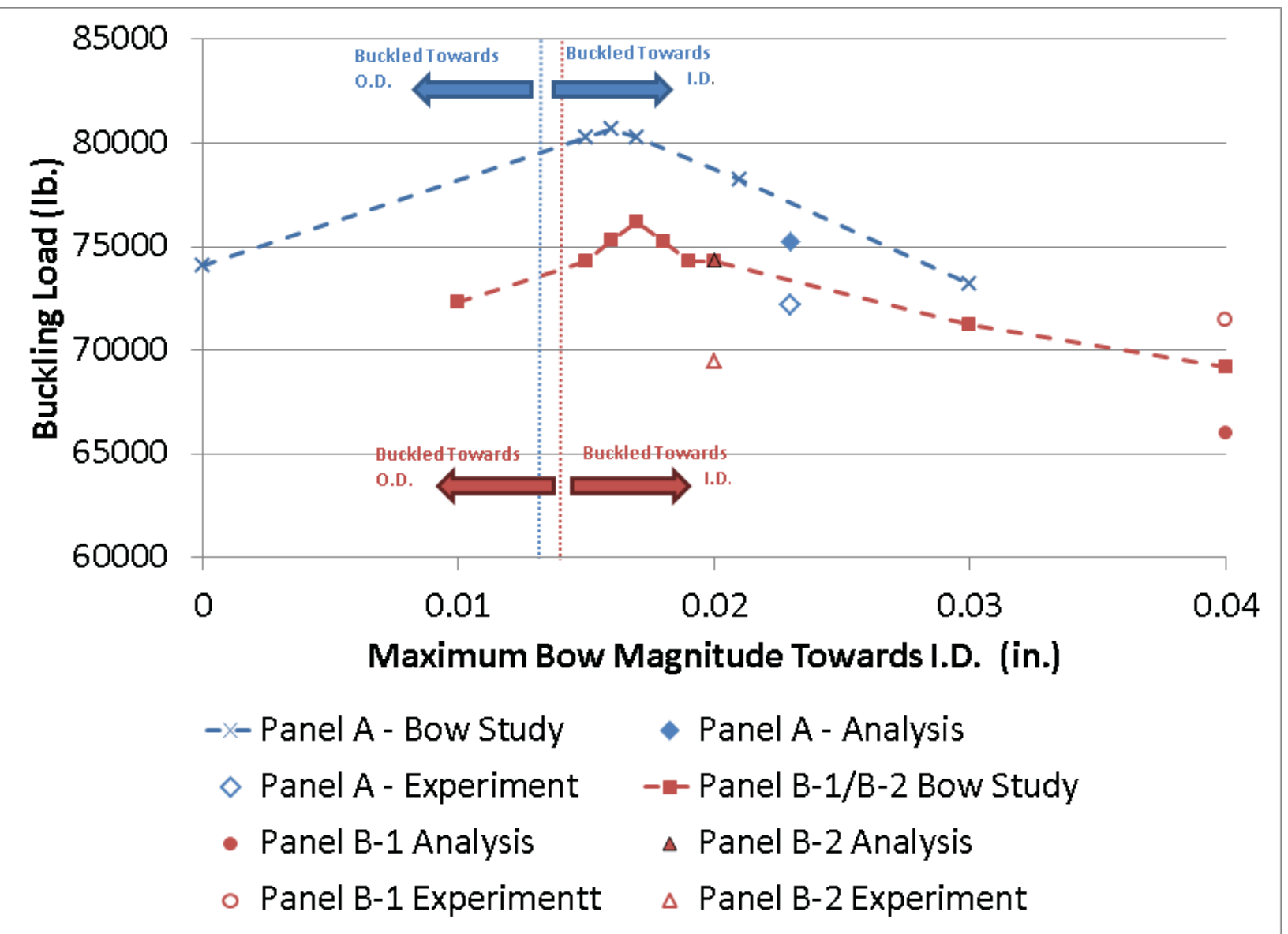

Figure 23. Study on sensitivity of buckling to geometric imperfections showing buckling load versus maximum bow deflection.

The original 2-D non-linear progressive collapse simulations incorporate measured imperfection data from the test panels. The bow shapes used in these analyses did not correspond to the arc segment used in the sensitivity study (see Figure 7). Moreover, the Panel A, and B-1 analyses follow the same trend as the sensitivity study. This implies that the imperfection shape (not just maximum deflection magnitude) influences the buckling load. The Panel B-2 analysis utilized a smooth spline shape, rather than an arc, but the predicted buckling load is the same as that from the sensitivity study which incorporate an arc segment-shaped imperfection with the same maximum deflection magnitude. Thus, not only the magnitude and shape of the geometric imperfections influence the buckling load, but the local gradients of the imperfections have an effect as well.

This is further demonstrated by the test results from Panel B-1 and B-2. The maximum, average imperfection magnitude was larger in Panel B-1, but the buckling load was higher. Thus, the maximum, average imperfection magnitude may not be a good measure of the geometric imperfections in the panel. However, this study shows that it may be possible to deliberately introduce some imperfections in the manufacturing process to increase the buckling load. Further studies will incorporate the full field (not average) imperfection data in an attempt to improve the analytical predictions. 


\section{V.B. Sensitivity to Fiber Misalignment}

To determine the sensitivity of the panel response to additional imperfections that may be introduced during the manufacturing process, several analyses were performed in which the orientation of the $45^{\circ}$ plies were perturbed from $45^{\circ}-50^{\circ}$ in Panel A and the $60^{\circ}$ plies were perturbed from $55^{\circ}-65^{\circ}$. Figure $24 \mathrm{a}$ exhibits that both panel stiffness and buckling load can be moderately affected by these fiber misalignments in the $45^{\circ}$ plies of Panel A. Additionally, the stiffness of the panel with 46.5 degree plies (a viable scenario with the test article) corresponds best with the Panel A test article stiffness. The 0 and 90 degree plies were not altered as it was assumed that their orientations do not vary during the ply lay-up process. Figure $24 \mathrm{~b}$ shows that stiffness of Panel B-1/B-2 is not sensitive to perturbations in the $60^{\circ}$ fiber angle, yet the plateau load is sensitive. This is consistent with the load-deflection slope data presented in Figures 12 and 13; the 6-ply configurations show less discrepancy in the slopes than the 8ply configurations. To further increase the accuracy of the analytical predictions, measurements of the fiber misalignment can be incorporated into the models.

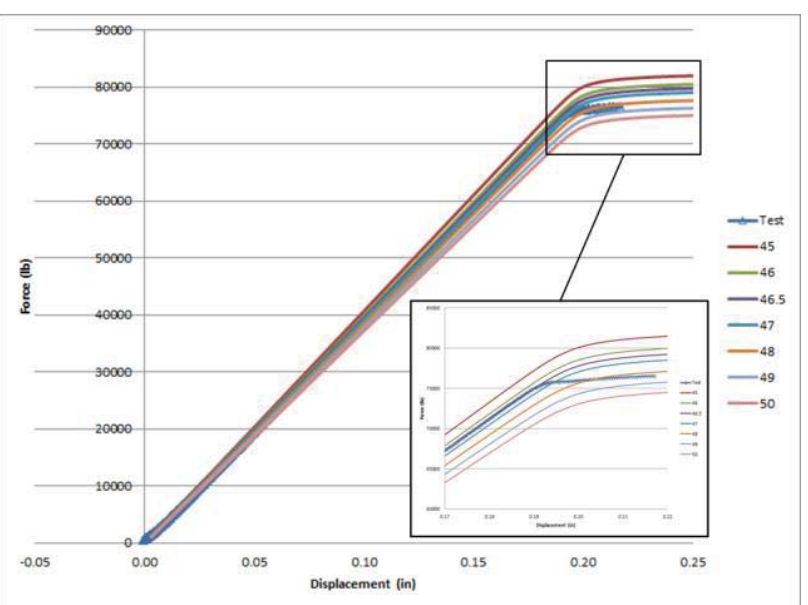

a) Panel $\mathbf{A}$

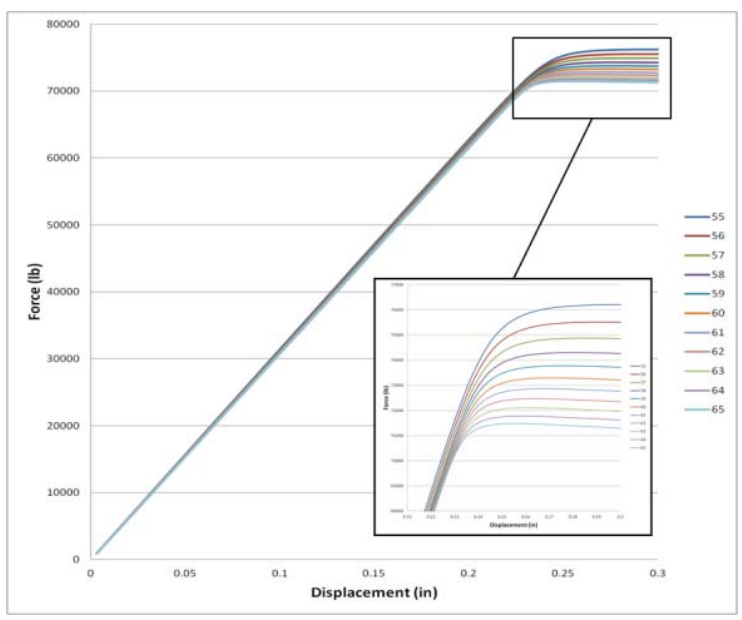

b) Panel B-1/B-2

Figure 24. Effect of fiber misalignment in $45^{\circ}$ and $60^{\circ}$ plies on load-deflection response of panels.

\section{V.C. Sensitivity to Loading Eccentricity}

To determine if eccentric application of the edge displacement would yield a change in the direction of buckling, a simulation was performed, accounting for some degree of eccentricity. Figure 25 shows the effect of eccentric loading on the through-thickness displacement of the edge of the sandwich panel. Assuming the difference between the displacements applied to the front face of the panel and the centerline of the panel is equal but opposite to the difference in the displacement applied to the back face of the panel, the centerline of the panel yields a rotation $\Phi$ given by

$$
\phi=\sin ^{-1}\left[0.05128 \frac{\Delta}{t}\right]
$$

where $\Delta$ is the centerline displacement and $t$ is the total thickness of the panel. The angle $\Phi$ is applied to the edge of the panel in the shell model as a rotation to simulate a through-thickness eccentricity in the applied edge displacement in the experiment. The angle used in the simulation is $20 \%$ of the buckling displacement from the linear eigenvalue solution and is calculated to be 0.12 degrees using Eq. (3). It is assumed that this level of eccentricity is present from the beginning of the analysis and is constant throughout the duration of the simulation.

Figure 26 shows the post-buckled shapes predicted using a non-linear analysis with a uniform edge displacement with eccentricity corresponding to a rotation of 0.12 degrees. Figure 27 shows a comparison in the loaddeflection behavior from the two simulations. These two figures show that
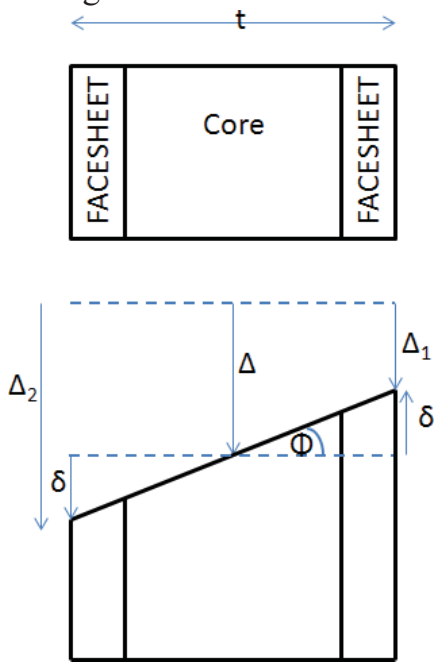

Figure 25. Diagram showing eccentric loading applied through the thickness of the panel leading to rotation of the panel edge. 
the buckling direction and the quantitative response of the panel is largely unaffected by the assumed misalignment. However, this is not an exhaustive study on loading eccentricity, and further simulations would be required to completely rule out any sensitivity to this imperfection.

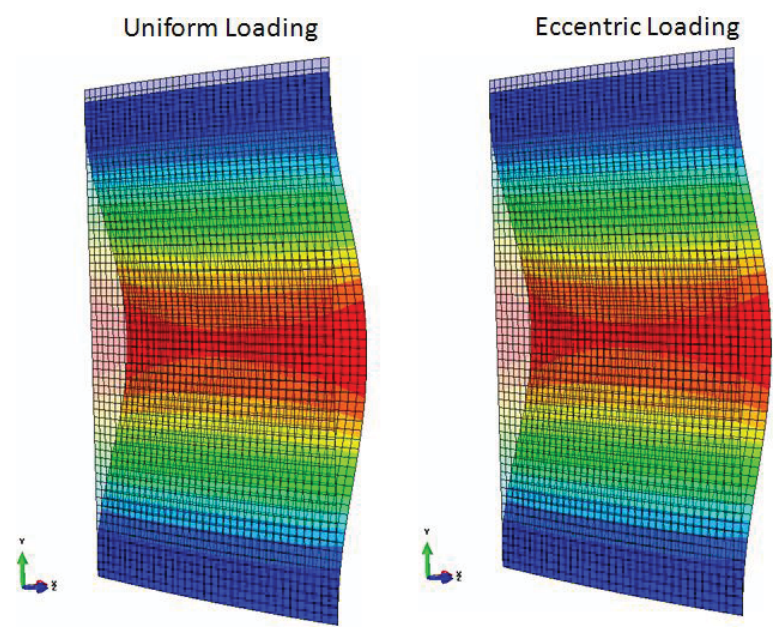

Figure 26. Resulting post-buckled shape with uniform applied displacement and simulated eccentric applied displacement.

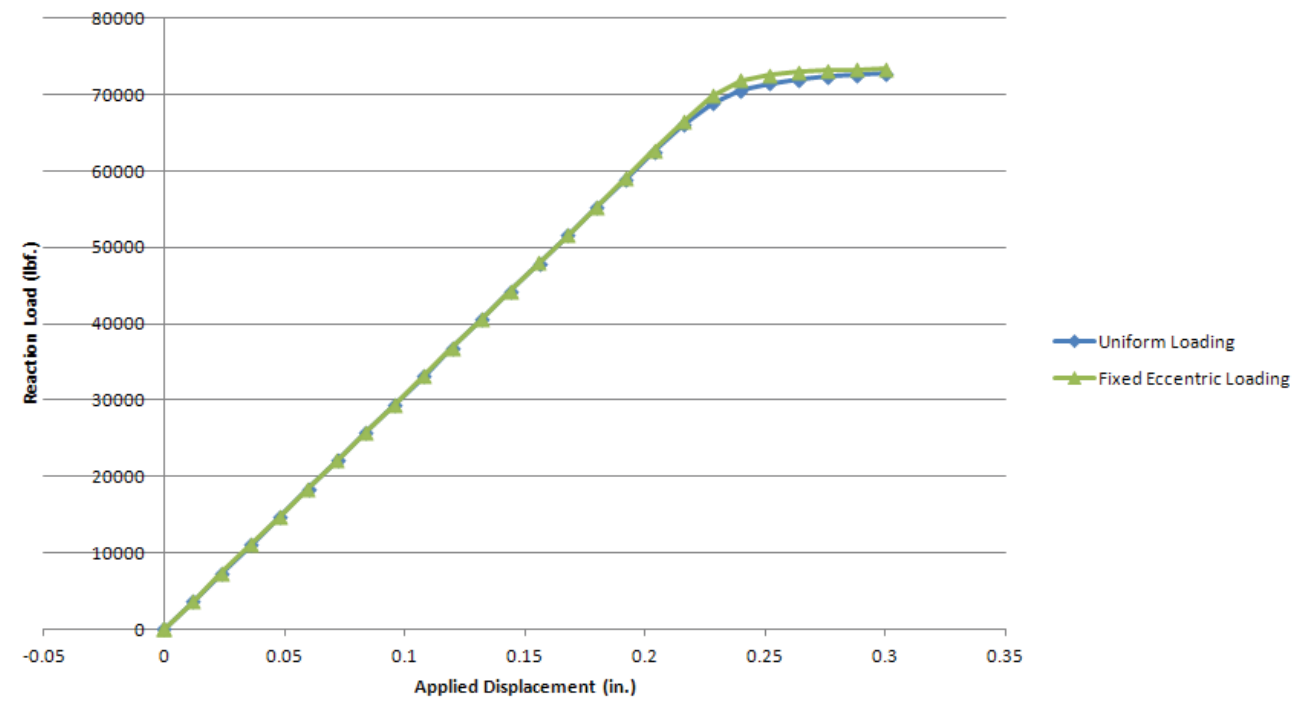

Figure 27. Reaction load versus applied displacement with uniform applied displacement and simulated eccentric applied displacement.

\section{Conclusions}

Five $3 \mathrm{ft}$. by $5 \mathrm{ft}$. curved, honeycomb sandwich panels (with four different configurations) were tested under compression until buckling. These panels represent arc segments from the full-scale barrel section of the HLLV fairing. Buckling occurred successfully in all five experiments prior to any damage or failure in the panels. Supplementary FEA was performed for each of the five panels. These analyses included linear eigenvalue analysis, 2-D, and 3-D geometrically non-linear progressive collapse analysis. The non-linear analyses incorporated measured geometric imperfections from the test specimens. The eigenvalue predictions fell within $24 \%$ of the experimental buckling loads. The 2-D non-linear FEA improved the predictions to within 19\%, and the 3-D nonlinear analysis further improved the predictions to within $11 \%$, however a slightly different seeding technique was used to introduce the geometric imperfections. All the predictions were well within the 0.65 shell buckling knockdown factor that is typically used for design. 
To further understand the reason for the discrepancy between analysis and experiment, three different imperfection studies were performed to investigate the sensitivity of panel buckling to geometric imperfections, fiber misalignment, and loading imperfection. All of these imperfections are viable defects that may occur during the manufacturing or testing process. Geometric imperfections in the panel can change the direction of buckling. If the direction of the imperfection is opposite the direction of buckling, then the imperfections actually serve to increase the buckling load of the panel. In addition, it was determined that the imperfection shape and local imperfection gradients influence the buckling results. In all of the analyses, an average imperfection shape was used. Future work will incorporate full field geometric imperfection data. The buckling response of the panels was also found to be sensitive to uniform fiber-misalignment in the plies. Both the panel stiffness and buckling load of 8-ply configurations were sensitive to misalignment in the $45^{\circ}$ plies, whereas the 6-ply configurations only exhibited a sensitivity in the buckling load to misalignment in the $60^{\circ}$ plies. Further studies can be performed to investigate the influence of non-uniform and/or measured fiber misalignment on the panel performance. Finally, an analysis was performed incorporating some loading eccentricity. The loading eccentricity did not affect the performance of the panel; however, the study conducted was not exhaustive.

Although the buckling of the arc segments in this work were not representative of the buckling of a fullcylinder, many of the practices presented here can be used to determine the same sensitivity of other structures to similar imperfections. In the future, such studies may lead to more comprehensive linear bucking knockdown factors for cylindrical shells that consider the impact and degree of different imperfections or defects separately Furthermore, these sensitivity studies can be utilized to arrive at critical manufacturing tolerances.

\section{Acknowledgments}

The authors would like to thank all of the Constellation Ares V, Composites for Exploration, and Space Launch System fairing team members that contributed to this work.

\section{References}

\footnotetext{
${ }^{1}$ National Aeronautics and Space Administration, "Buckling of Thin-Walled Circular Cylinders," NASA SP-8007, 1968.
}

${ }^{2}$ National Aeronautics and Space Administration, "Structural Design and Test Factors of Safety for Spaceflight Hardware," NASA-STD-5001A, 2008.

${ }^{3}$ Haynie, W. T., Hilburger, M. W., Bogge, M., Maspoli, M. Benedikt, K., "Validation of Lower-bound Estimates for Compression-loaded Cylindrical Shells," 53rd AIAA/ASME/ASCE/AHS/ASC Structures, Structural Dynamics, and Materials Conference, Honolulu, HI, 23-26 Apr., 2012.

${ }^{4}$ Hilburger, M. W., "Developing the Next Generation Shell Buckling Design Factors and Technologies," 53rd AIAA/ASME/ASCE/AHS/ASC Structures, Structural Dynamics, and Materials Conference, Honolulu, HI, 23-26 Apr., 2012.

${ }^{5}$ Kriegesmann, B., Hilburger, M. W., Rolfes, R., "The Effects of Geometric and Loading Imperfections on the Response and Lower-bound Buckling Load of a Compression-loaded Cylindrical Shell," 53rd AIAA/ASME/ASCE/AHS/ASC Structures, Structural Dynamics, and Materials Conference, Honolulu, HI, 23-26 Apr., 2012.

${ }^{6}$ Myers, D. E., Pineda, E. J., Zalewski, B. F., Kosareo, D. N., Kellas, S., "Buckling Testing and Analysis of Honeycomb Sandwich Panel Arc Segments of a Full-scale Fairing Barrel, Part 1: 8-ply In-autoclave Facesheets," NASA/TM-2013217822/PART1, 2013.

${ }^{7}$ Pineda, E. J., Myers, D. E., Kosareo, D. N., Zalewski, B. F., Dixon, G. D., "Buckling Testing and Analysis of Honeycomb Sandwich Panel Arc Segments of a Full-scale Fairing Barrel, Part 2: 6-ply In-autoclave Facesheets," NASA/TM-2013217822/PART2, 2013.

${ }^{8}$ Pineda, E. J., Myers, D. E., Kosareo, D. N.,Kellas, S., "Buckling Testing and Analysis of Honeycomb Sandwich Panel Arc Segments of a Full-scale Fairing Barrel, Part 3: 8-ply Out-of-autoclave Facesheets," NASA/TM-2013-217822/PART3, 2014 [under review].

${ }^{9}$ Myers, D. E., Pineda, E. J., Kosareo, D. N., Dixon, G. D., "Buckling Testing and Analysis of Honeycomb Sandwich Panel Arc Segments of a Full-scale Fairing Barrel, Part 4: 6-ply Out-of-autoclave Facesheets,” NASA/TM-2013-217822/PART4, 2014 [in preparation].

${ }^{10}$ Kellas, S., Lerch, B., Wilmoth, N., "Mechanical Characterization of In- and Out-of-autoclave Cured Composite Panels for Large Launch Vehicles,” SAMPE 2012, Baltimore, Maryland, May 21-24, 2012.

${ }^{11}$ Lockheed Martin, “Orion Materials and Design Allowables, Rev. D”, 2010.

${ }^{12}$ Collier Research Corp., Hypersizer Structural Sizing Software [online documentation], URL: http://www.hypersizer.com [cited 12 Dec. 2013].

${ }^{13}$ Hong, C. S., Jun S. M., "Buckling Behavior of Laminated Composite Cylindrical Panel with Initial Imperfections," Winter Annual Meeting of the American Society of Mechanical Engineers, co-sponsored by Pressure Vessels and Piping Division \& Aerospace Division, ASME, San Francisco, CA, Dec. 10-15, 1989, PVP-Vol. 183, AD-Vol. 18. 
${ }^{14}$ Hause, T., Librescu, L., Johnson, T. F., "Non-linear Response of Geometrically Imperfect Sandwich Curved Panels under Thermomechanical Loading," International Journal of Non-Linear Mechanics, Vol. 33, No. 6, 1998, pp. 1039-1059.

${ }^{15}$ Hause, T., Johnson, T. E., Librescu, L., "Effect of Face-sheet Anisotropy on Buckling and Postbuckling of Sandwich Plates," Journal of Spacecraft and Rockets, Vol. 37, No. 3, 2000, pp. 331-341.

${ }^{16}$ Hilburger, M. W., Nemeth, M. P., Starnes, J. H., Jr., "Nonlinear and Buckling Behavior of Curved Panels Subjected to Combined Loads," 42nd AIAA/ASME/ASCE/AHS Structures, Structural Dynamics and Materials Conference and Exhibit, Seattle, WA, 16-19 Apr., 2001.

${ }^{17}$ Hilburger, M. W., Starnes, J. H., Jr., "Effects of Imperfections on the Buckling Response of Compression-Loaded Composite Shells," International Journal of Non-Linear Mechanics, Vol. 37, 2002, pp. 623-643.

${ }^{18}$ Lynch, C., Murphy, A., Price, M., Gibson, A., "The Computational Post Buckling Analysis of Fuselage Stiffened Panels Loaded in Compression," Thin-Walled Structures, Vol. 42, 2004, pp. 1445-1464.

${ }^{19}$ Schultz, M. R., Nemeth, M. P., "Buckling Imperfection Sensitivity of Axially Compressed Orthotropic Cylinders," 51st AIAA/ASME/ASCE/AHS/ASC Structures, Structural Dynamics, and Materials Conference, Orlando, FL, 12-15 Apr., 2010.

${ }^{20}$ Singer, J., Arboz, J., T. Weller, Buckling Experimental Methods in Buckling Thin Walled Structures, Basic Concepts, Columns, Beams and Plates - Volume 1, John Wiley \& Sons, Inc., New York, 1998

${ }^{21}$ Kosareo, D. N., Oliver, S. T., Bednarcyk, B. A. 1/6th Arc-segment Buckling Panel Design and Analysis. NASA/TM, [in publishing] 2013.

${ }^{22}$ Jones, R. M., Mechanics of Composite Materials, $2^{\text {nd }}$ Edition, Taylor \& Francis, Inc., Philadelphia, PA, 1999.

${ }^{23}$ Zalewski, B. F., Dial, W. B., Bednarcyk, B. A., "Methods for Assessing Honeycomb Sandwich Panel Wrinkling Failures," NASA/TM-2012-217697, 2012.

${ }^{24}$ Vinson, J. R., The Behavior of Sandwich Structures of Isotropic and Composite Materials, Technomic Publishing Co., Lancaster, PA, 1999.

${ }^{25}$ Ley, R. P., Lin, W., Mbanefo, U., “Facesheet Wrinkling in Sandwich Structures,” NASA/CR-1999-208994, 1999. 